DOI: http://dx.doi.org/10.1016/j.gca.2017.02.024

Reference: GCA 10171

To appear in:

Geochimica et Cosmochimica Acta

Received Date:

30 July 2016

Accepted Date:

18 February 2017

Please cite this article as: Sim, M.S., Paris, G., Adkins, J.F., Orphan, V.J., Sessions, A.L., Quantification and isotopic analysis of intracellular sulfur metabolites in the dissimilatory sulfate reduction pathway, Geochimica et Cosmochimica Acta (2017), doi: http://dx.doi.org/10.1016/j.gca.2017.02.024

This is a PDF file of an unedited manuscript that has been accepted for publication. As a service to our customers we are providing this early version of the manuscript. The manuscript will undergo copyediting, typesetting, and review of the resulting proof before it is published in its final form. Please note that during the production process errors may be discovered which could affect the content, and all legal disclaimers that apply to the journal pertain. 


\section{Quantification and isotopic analysis of intracellular sulfur metabolites in the dissimilatory sulfate reduction pathway}

*Min Sub Sim ${ }^{1,2}$, Guillaume Paris ${ }^{1,3}$, Jess F. Adkins ${ }^{1}$, Victoria J. Orphan ${ }^{1}$, Alex L. Sessions ${ }^{1}$

${ }^{1}$ Division of Geological and Planetary Sciences, California Institute of Technology, Pasadena, CA 91125, USA

${ }^{2}$ School of Earth and Environmental Sciences, Seoul National University, Seoul 08826, South Korea

${ }^{3}$ Centre de Recherches Pétrographiques et Géochimiques, UMR 7358 CNRS-

UL, Vandoeuvre-lès-Nancy, 54500 France

*Address correspondence to Min Sub Sim, mssim@snu.ac.kr 


\begin{abstract}
Microbial sulfate reduction exhibits a normal isotope effect, leaving unreacted sulfate enriched in ${ }^{34} \mathrm{~S}$ and producing sulfide that is depleted in ${ }^{34} \mathrm{~S}$. However, the magnitude of sulfur isotope fractionation is quite variable. The resulting changes in sulfur isotope abundance have been used to trace microbial sulfate reduction in modern and ancient ecosystems, but the intracellular mechanism(s) underlying the wide range of fractionations remains unclear. Here we report the concentrations and isotopic ratios of sulfur metabolites in the dissimilatory sulfate reduction pathway of Desulfovibrio alaskensis. Intracellular sulfate and APS levels change depending on the growth phase, peaking at the end of exponential phase, while sulfite accumulates in the cell during stationary phase. During exponential growth, intracellular sulfate and APS are strongly enriched in ${ }^{34} \mathrm{~S}$. The fractionation between internal and external sulfate is up to 49\%, while at the same time that between external sulfate and sulfide is just a few permil. We interpret this pattern to indicate that enzymatic fractionations remain large but the net fractionation between sulfate and sulfide is muted by the closed-system limitation of intracellular sulfate. This 'reservoir effect' diminishes upon cessation of exponential phase growth, allowing the expression of larger net sulfur isotope fractionations. Thus, the relative rates of sulfate exchange across the membrane versus intracellular sulfate reduction should govern the overall (net) fractionation that is expressed. A strong reservoir effect due to vigorous sulfate reduction might be responsible for the well-established inverse correlation between sulfur isotope fractionation and the cell-specific rate of sulfate reduction, while at the same time intraspecies differences in sulfate uptake and/or exchange rates could account for the significant scatter in this relationship. Our approach, together with ongoing investigations of the kinetic isotope fractionation by key enzymes in the sulfate reduction pathway, should provide an empirical basis for a quantitative model relating the magnitude of microbial isotope fractionation to their environmental and physiological controls.
\end{abstract}




\section{Introduction}

Since Thode et al. (1951) first demonstrated that the $\mathrm{H}_{2} \mathrm{~S}$ produced by microbial sulfate reduction is depleted in ${ }^{34} \mathrm{~S}$ relative to the reactant sulfate, isotopic fractionation between sulfate and sulfide has been widely used to trace the activity of sulfate reducing microbes in modern and ancient ecosystems (Fry, 1991; Canfield and Teske, 1996; Wortmann et al., 2001; Druhan et al., 2008). Given the large variations in natural abundance of sulfur isotopes up to several percent, numerous attempts have been made to relate the magnitude of isotopic fractionation to their genetic (Detmers et al., 2001), evolutionary (Pellerin et al., 2015), and environmental controls, including levels of electron acceptor or donor (Harrison and Thode, 1958; Chambers et al., 1975; Habicht et al., 2005; Hoek et al., 2006; Sim et al., 2011a; Leavitt et al., 2013), limitation of other nutrients (Sim et al., 2012), and temperature (Canfield et al., 2006; Mitchell et al., 2009). These studies provide a general consensus that limiting the supply of electron donor to the sulfate reduction pathway leads to larger sulfur isotope effects, while depletion of terminal electron acceptor, sulfate, decreases the magnitude of fractionation (see Figure 6 of Bradley et al., 2016). Such qualitative framework helps to extract environmental information from the sulfur isotope fractionation records preserved in sediments and old rocks (Jones et al., 2013; Sim et al., 2015; Raven et al., 2016). Yet, the use of sulfur isotopes as a quantitative geochemical proxy is rather complicated, because all culture experiments show a nonlinear and species-specific relationship between isotope effects and environmental stimuli (Ono et al., 2014; Wing and Halevy, 2014). These limitations are rooted, in part, in the experimental shortcomings that microbial sulfur isotope fractionation has been explored primarily as a single net effect, although it involves a series of enzymatic reactions.

So far, not much is experimentally known about the intracellular processes responsible for large variations in microbial sulfur isotope fractionations, spanning from -3 to 66\%o (Harrison and Thode, 1958; Sim et al., 2011b). Theoretical models have provided a basis for linking isotopic fractionation to internal cellular processes, but remain largely untested. The linear metabolic network model, first proposed by Rees (1973), has been modified to meet new experimental observations (Brunner and Bernasconi, 2005; Johnston et al., 2007; Wing and Halevy, 2014; Bradley et al., 2016). Here the kinetic isotope effects assigned to each enzymatic reaction define the possible range of sulfur isotope fractionation. These models invoke the reversibility of each enzymatic reaction, that is, the ratio of backward to forward fluxes, as a mechanism underlying the varying fractionations (Figure 1). Since reversibility is ultimately constrained by the concentrations of substrates and products (Wing and Halevy, 2014), measuring the intracellular sulfur metabolite levels and their isotopic compositions provides a direct means of bridging the gap between theoretical model and experimental observations.

Here, we report a new analytical approach to determining the concentrations and isotopic compositions of intracellular sulfur metabolites, sulfate, APS, and sulfite, in sulfate-reducing microbes. Reliable and reproducible measurements are achieved via preparative ion chromatography coupled to isotopic analysis by MC-ICP-MS (Paris et al., 2013). The ${ }^{33}$ S-dilution technique is employed to track background contamination and validate the measurements. Using a series of batch cultures of Desulfovibrio alaskensis, we demonstrate that the intracellular sulfur metabolite levels and their isotopic compositions fluctuate throughout the growth phase, and the relative limitation of intracellular sulfate ('reservoir effect') strongly constrain the expressed sulfur isotope fractionation during microbial sulfate reduction.

\section{Experimental Methods}

\subsection{Batch incubation}

Three independent batch experiments were conducted with a marine sulfate-reducing bacterium, Desulfovibrio alaskensis. D. alaskensis was incubated in a chemically defined, carbonate 
buffered medium containing (per liter): $\mathrm{NaHCO}_{3}, 5 \mathrm{~g} ; \mathrm{Na}_{2} \mathrm{SO}_{4}, 3 \mathrm{~g} ; \mathrm{KH}_{2} \mathrm{PO}_{4}, 0.2 \mathrm{~g}$; NaCl 21g; $\mathrm{MgCl}_{2} \cdot 6 \mathrm{H}_{2} \mathrm{O}, 3.1 \mathrm{~g} ; \mathrm{KCl}, 0.5 \mathrm{~g} ; \mathrm{CaCl}_{2} \cdot 2 \mathrm{H}_{2} \mathrm{O}, 0.15 \mathrm{~g}$; resazurin, $1 \mathrm{mg} ; 1 \mathrm{ml}$ of trace element solution SL-10 (Widdel et al., 1983); $10 \mathrm{ml}$ of vitamin solution described as a part of DSMZ medium 141 (catalogue of strains 1993; DSMZ, Braunschweig, Germany); and $1 \mathrm{ml}$ of tungsten-selenium stock solution (4 mg of $\mathrm{Na}_{2} \mathrm{WO}_{4} \cdot 2 \mathrm{H}_{2} \mathrm{O}$ and $3 \mathrm{mg}$ of $\mathrm{Na}_{2} \mathrm{SeO}_{3} \cdot 5 \mathrm{H}_{2} \mathrm{O}$ per $1 \mathrm{~L}$ of $0.01 \mathrm{M} \mathrm{NaOH}$ ). Cultures contained lactate $(22 \mathrm{mM})$ as the sole organic electron donor, and sodium ascorbate $(5 \mathrm{mM})$ and titanium (III) chelated by nitrilotriacetate (NTA; $60 \mu \mathrm{M}$ ) as reducing agents. The completed medium was titrated to $\mathrm{pH} 7.2$ and sterilized by filtration under $80 \% \mathrm{~N}_{2}-20 \% \mathrm{CO}_{2}$ gas. A preculture grown in the same conditions was used as inoculum. Prior to inoculation, the cells were washed three times by anaerobic centrifugation and resuspension in phosphate buffer solution $(0.35 \mathrm{M} \mathrm{NaCl}, 0.05 \mathrm{M}$ potassium phosphate, $\mathrm{pH}$ of 7.0) to minimize the carryover of sulfate and sulfide. For the first and third sets of experiments, three $500 \mathrm{ml}$ cultures were inoculated in parallel, and each was sacrificed to recover intracellular sulfur compounds at different growth stages, while only stationary phase cells were tested for the second experiment. Since the concentrations and sulfur isotope compositions of intracellular sulfur metabolites turned out to be sensitive to the physiological status of the cell, biological replicates could be assessed by analyzing independently-prepared samples only from a comparable growth stage. Here, two early stationary phase samples provided a measure of biological reproducibility (series 1 and 2). All cultures were incubated at $32^{\circ} \mathrm{C}$ with $175 \mathrm{rpm}$ agitation, and growth was monitored by measuring the optical density at $660 \mathrm{~nm}$ (A660). A conversion factor for optical density to dry weight was determined for A660 of 0.1 as $40 \mu \mathrm{g} / \mathrm{mL}$.

\subsection{Extracellular metabolites}

Samples for the quantification of organic acids were collected at intervals throughout incubation by filtering $1 \mathrm{~mL}$ of culture through a $33 \mathrm{~mm}$-diameter, $0.2 \mu \mathrm{m}$-pore membrane (Millipore, Cork, Ireland) and stored at $-80{ }^{\circ} \mathrm{C}$ until analysis. All collected samples were analyzed together using an Agilent 1100 HPLC (Agilent Technologies, Santa Clara, CA, USA). Separation was achieved on an Aminex $87 \mathrm{H}$ column (300 $\mathrm{mm} \times 7.8 \mathrm{~mm}$, Bio-Rad, Hercules, CA, USA) with $8 \mathrm{mM}$ sulfuric acid as an isocratic mobile phase at $0.6 \mathrm{ml} / \mathrm{min}$, and concentrations of lactate and acetate were measured with both a UV-visible diode array detector at $206 \mathrm{~nm}$ referenced to $260 \mathrm{~nm}$ and a refractive index detector. Acetate and lactate standard solutions were prepared by diluting stock solutions of $110 \mathrm{mM}$ and $70 \mathrm{mM}$, respectively, and the calibration plot was obtained by linear regression of peak-area against concentration. Dissolved sulfate and sulfide in the medium were collected multiple times during the incubation. A $1 \mathrm{~mL}$ aliquot of culture sample was extracted, filtered through a $0.2 \mu \mathrm{m}$ membrane filter, and mixed with $0.2 \mathrm{ml}$ of zinc acetate $(1 \mathrm{M})$ solution. Samples were stored at $4{ }^{\circ} \mathrm{C}$ until analysis. Sulfate concentrations in the medium were determined on a Dionex DX 500 ion chromatograph (IC) equipped with an AS11-HC column (Dionex, Sunnyvale, CA, USA). The sulfate eluate was collected for isotopic analysis. Sulfide concentration was measured using a modified methylene blue assay (Cline, 1969), and one $\mu \mathrm{mol}$ of precipitated zinc sulfide was converted to sulfuric acid for isotopic analysis on the MC-ICP-MS (see section 2.4). Zinc sulfide was washed with deionized water (DW) three times to remove residual sulfate, and oxidized to sulfate in $15 \% \mathrm{H}_{2} \mathrm{O}_{2}$ and $0.5 \mathrm{mM} \mathrm{Fe}(\mathrm{III}) / \mathrm{NTA}$ at $75^{\circ} \mathrm{C}$ for $24 \mathrm{~h}$. The amount of sulfate produced from a known amount of zinc sulfide was examined via ion chromatography, confirming the complete conversion within the analytical error (5\%). The oxidation of zinc sulfide to sulfate by $\mathrm{H}_{2} \mathrm{O}_{2}$ was also described in Raven $e t$ al. (2016). After oxidation and drying, samples were dissolved in $5 \mathrm{mM} \mathrm{HCl}$, and any remaining precipitate was removed by centrifugation. The supernatant solution was then loaded onto AG1X8 anion exchange resin. Cations were removed by rinsing the resin with $3 \mathrm{ml}$ of DW for four times, and sulfate was eluted with $3.6 \mathrm{ml}$ of $0.5 \mathrm{M} \mathrm{HNO}_{3}$ (Paris et al., 2014). 


\subsection{Intracellular metabolites}

To recover intracellular metabolites, a whole culture $(0.5 \mathrm{~L})$ was harvested by centrifugation at $13,000 \mathrm{~g}$ for $15 \mathrm{~min}$ at $32^{\circ} \mathrm{C}$. Cells were then resuspended and washed three times with anaerobic cold saline solution $\left(2 \% \mathrm{NaCl}, 0^{\circ} \mathrm{C}\right)$. For the early stationary phase samples, a cell suspension was split into two aliquots before washing and processed in parallel throughout the following steps, which served as a measure of procedural reproducibility. Cypionka (1989) described that intracellular sulfate was not released by washing with the sulfate-free solution, although excess extracellular sulfate allowed the rapid exchange of sulfate across the membrane. Dissolved sulfur compounds in the medium were removed by thorough washing with sulfate well below the levels of the fresh saline solution (up to $0.2 \mu \mathrm{M}$ ) in the final wash. Washed cells were distributed into microcentrifuge tubes, flash frozen in liquid $\mathrm{N}_{2}$, and stored at $-80^{\circ} \mathrm{C}$ until extraction. The use of cold saline solution minimizes cellular damage (Wu and $\mathrm{Li}, 2013$ ) and sulfate reduction (Warthmann and Cypionka, 1990) during the washing procedure. Intracellular sulfur metabolites were extracted using a modified cold methanol protocol after Maharjan and Ferenci (2003). The frozen pellet was thawed and resuspended in $0.6 \mathrm{~mL}$ DW in an anaerobic glove box (Coy Manufacturing Co., Ann Arbor, MI, USA). An equal volume of cold methanol was added to the cell suspension, resulting in a final methanol concentration of $50 \% \mathrm{v} / \mathrm{v} .20 \mu \mathrm{L}$ of $\mathrm{ZnCl}_{2}$ solution $(50 \mathrm{mM})$ was added to precipitate dissolved sulfide as $\mathrm{ZnS}$. Otherwise, dissolved sulfide can be oxidized to sulfur oxyanions when exposed to air. It has been reported that ascorbate also serves as a sulfide anti-oxidant (KellerLehmann et al., 2006), but this did not prevent the oxidation of sulfide to thiosulfate in our experimental conditions. After mixing, the sample was left on dry ice for $30 \mathrm{~min}$ and then thawed on ice for $10 \mathrm{~min}$. The supernatant was then recovered by centrifugation. $100 \mu \mathrm{L}$ of $13 \mathrm{mM}$ formaldehyde was added, which effectively suppresses the oxidation of sulfite during the subsequent anion-exchange chromatographic step (Lindgren and Cedergren, 1982; Keller-Lehmann et al., 2006). APS is known to hydrolyze rapidly under acidic conditions (Kohl et al., 2012) but rather stable around neutral $\mathrm{pH}$. Based on our tests, without an aid of enzymes, APS was not decomposed in 2 hours at $32^{\circ} \mathrm{C}$ within the precision of measurement (5\%). Note that after harvesting cells, the temperature was kept lower than $4^{\circ} \mathrm{C}$, and excess methanol and zinc helped quench the enzymatic activities (Kandlbinder et al., 2000; Nony et al., 2005). Sulfur metabolites in the cell extract, including sulfate, sulfite, and APS, were quantified and collected by IC using a gradient elution with $\mathrm{KOH}$ as mobile phase. The optimized gradient profile and the resulting separation of sulfur species are detailed in Figure 2. Two detectors were used, conductivity and UV absorbance. Samples were mixed with an equal volume of DW before loading into a $1.44 \mathrm{~mL}$ injection loop, to avoid the high methanol content swelling the resin and building up high pressure in the column. The eluatant fraction corresponding to each targeted sulfur analyte was collected for isotopic analysis. Collected analytes were quantitatively converted to sulfate by hydrolysis under acidic conditions (APS) or oxidation with $\mathrm{H}_{2} \mathrm{O}_{2}$ (sulfite) at $60{ }^{\circ} \mathrm{C}$.

\subsection{Isotopic analyses}

Samples containing dissolved sulfate were dried on a hot plate and diluted in $5 \% \mathrm{HNO}_{3}$ to a sulfate concentration of $20 \mu \mathrm{M}$ to match the in-house $\mathrm{Na}_{2} \mathrm{SO}_{4}$ working standard. $\mathrm{NaOH}$ was then added to yield equimolar $\mathrm{Na}$ and $\mathrm{SO}_{4}{ }^{2-}$. Isotopic analysis was conducted on a Thermo Fischer Scientific Neptune Plus multi-collector inductively coupled plasma mass spectrometer (MC-ICP-MS), operated in medium resolution following the method described by Paris et al. (2013). Samples were introduced to plasma via an ESI PFA-50 nebulizer and Cetac Aridus II desolvator. Sulfur isotope ratios of the sample and working standard were measured in alternating 50 cycles of $4.194 \mathrm{~s}$ integration time, and instrumental blank was estimated after each sample block. The mean blank value was subtracted from the measured signal for each mass. The measured ${ }^{34} \mathrm{~S} /{ }^{32} \mathrm{~S}$ and ${ }^{33} \mathrm{~S} /{ }^{32} \mathrm{~S}$ ratios were 
calibrated using a linear interpolation between the two bracketing standard values. Sulfur isotope ratios are reported here using the conventional delta notation:

$$
\delta^{x} S={ }^{x} R_{\text {sample }} /{ }^{x} R_{V C D T}-1
$$

where ${ }^{\mathrm{x}} \mathrm{R}_{\text {sample }}$ and ${ }^{\mathrm{x}} \mathrm{R}_{\mathrm{VCDT}}$ are the isotopic ratios $\left({ }^{33} \mathrm{~S} /{ }^{32} \mathrm{~S}\right.$ or $\left.{ }^{34} \mathrm{~S} /{ }^{32} \mathrm{~S}\right)$ of sample and Vienna-Cañon Diablo Troilite (VCDT), respectively. Our working standard was calibrated against the IAEA S-1 reference material $\left(\delta^{34} \mathrm{~S}_{\mathrm{VCDT}}=-0.3 \%\right.$, $\delta^{33} \mathrm{~S}_{\mathrm{VCDT}}=-0.055 \%$ ) and has a $\delta^{4} \mathrm{~S}$ value of $-1.55 \% \circ \pm 0.16(2 \sigma)$ and $\delta^{33} \mathrm{~S}$ of $-0.77 \pm 0.17 \%$ on the VCDT scale. The $\delta^{34} \mathrm{~S}_{\mathrm{VCDT}}$ values of three IAEA standard $\mathrm{BaSO}_{4}$ solutions, SO5, SO6, and NBS127, measured against this working standard agree within uncertainty with the published values (Paris et al., 2013). Analytic reproducibility for $\delta^{4} S$ and $\delta^{3} S$ has been previously evaluated as a $2 \sigma$ of $0.2 \%$ (Paris et al., 2013).

\subsection{Blank detection by isotope dilution}

The use of MC-ICP-MS lowers the detection limit of sulfur isotope analyses down to a few nmol S (Paris et al., 2013), an essential capability for measuring trace intracellular metabolites. At these levels, however, background contamination during sample work-up (i.e. the blank) can be problematic. Incorporation of exogenous sulfate is the most worrisome given its abundance in nature, and can be very hard to detect based on $\delta^{4} \mathrm{~S}$ values alone. Highly variable concentrations make the conventional approach of preparing and analyzing method blanks perilous. Thus, an internal control was required to assess the blank contribution to measured isotope ratios, especially for low-abundance intracellular analytes. Given that the ICP-MS can accurately measure ${ }^{32} \mathrm{~S},{ }^{33} \mathrm{~S}$, and ${ }^{34} \mathrm{~S}$, we employed a ${ }^{33} \mathrm{~S}$ label in the cultures for this purpose, as described below.

Changes in ${ }^{34} \mathrm{~S} /{ }^{32} \mathrm{~S}$ and ${ }^{33} \mathrm{~S} /{ }^{32} \mathrm{~S}$ ratios between species $\mathrm{A}$ and $\mathrm{B}$ will be proportionate, depending on the mass difference upon isotopic substitution. This yields the well-known massdependent fractionation relationship

$$
\frac{{ }^{33} R_{A}}{{ }^{33} R_{B}}=\left(\frac{{ }^{34} R_{A}}{{ }^{34} R_{B}}\right)^{0.515}
$$

Although described by a power law, the mass-dependent fractionation of sulfur isotopes is nearly linear in $\delta$ for small fractionations, such that sulfur from all modern terrestrial sources obeys the relationship $\delta^{33} \mathrm{~S} \approx 0.515 \cdot \delta^{34} \mathrm{~S}$. This relationship is termed the terrestrial mass-dependent array (Farquhar et al., 2003). Addition of ${ }^{33} \mathrm{SO}_{4}{ }^{2-}$ label into the culture medium shifts our experiments to a separate but parallel mass-dependent array (Figure 3A), and provides a clear means to distinguish experimental analytes from laboratory blank. For the first and second sets of experiments, $1 \mathrm{~mL}$ of 35 $\mathrm{mM} \mathrm{Na}{ }_{2}^{33} \mathrm{SO}_{4}$ solution was added per $1 \mathrm{~L}$ medium so that $\delta^{33} \mathrm{~S}$ of initial sulfate was adjusted upward by $\sim 200 \%$ (Figure $3 \mathrm{~A}$ ). The $\mathrm{Na}_{2}{ }^{33} \mathrm{SO}_{4}$ was prepared from ${ }^{33} \mathrm{~S}$-elementals sulfur (99.8\%, Trace Sciences International Inc., Wilmington, DE, USA), following the procedure outlined in Dawson et al. (2016). S analytes derived entirely from this supplied sulfate (e.g. APS, sulfite, sulfide) will necessarily have $\delta^{3} \mathrm{~S}$ and $\delta^{4} \mathrm{~S}$ values that stay on this same experimental array, regardless of how strongly they are fractionated. Introduction of contaminant sulfur, which resides on the terrestrial array, will force the analyte $\delta^{3} \mathrm{~S}$ and $\delta^{4} \mathrm{~S}$ values off the experimental array (Figure 3B). In this way we simultaneously used ${ }^{34} \mathrm{~S} /{ }^{32} \mathrm{~S}$ ratios to track sulfur isotope fluxes in the cell and ${ }^{33} \mathrm{~S} /{ }^{32} \mathrm{~S}$ ratios to assess potential blank contributions. We note that this system does not provide any visibility into contamination by other experimental species, for example extracellular sulfate that might end up in the intracellular sulfate fraction. Instead, cross-contamination among sulfur metabolites could be limited by manipulating the experimental conditions as described in section 2.3. 


\subsection{Data processing}

Average specific growth rates $\left(\mathrm{hr}^{-1}\right)$ were derived from the slope of the natural logtransformed linear regression of optical density, and growth yields were calculated as the increase in optical density per sulfate consumed. The specific sulfate reduction rate (sSRR) during the same interval was calculated from the specific growth rate and growth yield (Sim et al., 2011a).

$$
\operatorname{sSRR}\left(M \cdot A 660^{-1} \cdot \text { time }^{-1}\right)=\frac{\text { specific growth rate }\left(\text { time }^{-1}\right)}{\text { growth yield }\left(A 660 \cdot M^{-1}\right)}
$$

To assess the sulfur isotope mass balance, the concentration-weighted average of extracellular sulfate and sulfide isotope compositions, $\delta^{34} \mathrm{~S}$, was evaluated and compared with the $\delta^{34} \mathrm{~S}$ values of initial sulfate. When multiple cultures were set up for the experiment, $\mathrm{Na}_{2}{ }^{33} \mathrm{SO}_{4}$ solution was added together with the inoculum to each incubation medium. The resulting bottle-to-bottle variation in the $\delta^{33} \mathrm{~S}$ values of total sulfur was up to $6 \%$, so that ${ }^{33} \mathrm{~S}$ was not used to measure the mass balance closure throughout the experiment. The isotope enrichment factor $\left({ }^{34} \varepsilon\right)$ was calculated using an approximate solution to the Rayleigh distillation equations:

$$
\ln \left(\delta^{34} S_{r}+1\right)=\ln \left(\delta^{34} S_{o}+1\right)-\varepsilon \cdot \ln (f)
$$

where $f$ is the fraction of the remaining sulfate and $\delta^{34} \mathrm{~S}_{o}$ and $\delta^{34} \mathrm{~S}_{r}$ are sulfur isotope compositions of the initial sulfate and remaining sulfate, respectively (Mariotti et al., 1981). Plotting $\ln \left(\delta^{34} \mathrm{~S}_{\mathrm{r}}+1\right)$ versus - $\ln (\mathrm{f})$ yielded a straight line, indicative of a constant fractionation throughout the course of exponential growth. The slope of a linear regression through the data was taken as a measure of the average enrichment factor for the batch culture experiment. As we have defined it, positive values of $\varepsilon$ represent the depletion of heavy isotopes in the product (sulfide). All analytical errors were propagated via either Monte Carlo simulation $(n=5,000)$ or first-order Taylor series expansion (Bevington and Robinson, 2002).

\section{Results}

Inoculated with $21 \mathrm{mM}$ sulfate and $22 \mathrm{mM}$ lactate, cultures of D. alaskensis reduced about a half of sulfate into sulfide and oxidized all lactate to acetate within $60 \mathrm{hr}$, reflecting that the reduction of one sulfate to sulfide requires the oxidation of two lactate molecules (Figure 4; Table 1). After lactate depletion caused growth phase to end, concentrations of metabolic reactants and products remained largely unchanged. The average growth rate and yield during the growth phase were $0.10 \mathrm{hr}$ ${ }^{1}$ and 22.6 A660/ $\mathrm{M} \mathrm{SO}_{4}{ }^{2-}$, respectively, which implies a specific sulfate reduction rate of $4.4 \mathrm{mM} \mathrm{SO}_{4}{ }^{2-}$ /A660/hr (Table 2). For experimental efficiency and precision, the optical density was used as a measure of cell abundance, while the rate of sulfate reduction was often normalized to the number of cells in previous literature (Table 2). The average ${ }^{34} \mathrm{~S}$ enrichment factor $\left({ }^{34} \varepsilon\right.$ ) was $3.8 \%$ (Table 2), and the $\delta^{34} \mathrm{~S}$ mass balance was always retained within the precision of measurements (Figure 4D). The minimal fractionation by D. alaskensis is consistent with Leavitt et al. (2014) that reported ${ }^{34} \varepsilon$ values of $4.3 \%$ and $5.9 \%$ o coupled with the oxidation of formate and lactate, respectively. A slight reduction in growth rate occurred as lactate concentration dropped below $5 \mathrm{mM}$ (Figure 4; Table 2). Gradual decrease in lactate concentration appeared to influence other growth kinetic parameters and sulfur isotope fractionation, but these variations did not exceed analytical errors until cells entered into stationary phase (Table 2), although a negative shift in the $\delta^{34} S_{\text {sulfide }}$ value after the cessation of growth was notable (Series 1 in Table 1).

Intracellular metabolite samples were collected at different growth stages, from exponential growth through the death phase (Table 1). Intracellular sulfate content was less than $1 \mathrm{nmol} / \mathrm{mg}$ (dry weight) at the mid-log phase, but cells rapidly accumulated above $30 \mathrm{nmol} / \mathrm{mg}$ sulfate as the growth rate declined. This accumulated sulfate was then slowly depleted throughout the later stationary phase (Figure 5). Intracellular APS contents ranged from below detection to $0.14 \mathrm{nmol} / \mathrm{mg}$ (Figure 5). 
Although APS content peaked during the transitional phase, its ratio to intracellular sulfate decreased over time. Intracellular sulfite contents were more than an order of magnitude lower than those of APS throughout exponential and stationary phases (Figure 5). However, when cells entered the death phase, APS content decreased rapidly, while sulfite showed little change. Thiosulfate was detectable but could not be reliably measured due to the interference with highly abundant substances such as phosphate.

Sulfur isotope ratios of intracellular metabolites were measured from the ${ }^{33} \mathrm{~S}$-spiked experiments. Intracellular sulfate was always enriched in ${ }^{34} \mathrm{~S}$ relative to sulfate in the medium (Figure 6A). Although obtained in a single biological replicate, this enrichment was as large as $49 \%$ at the late exponential growth phase. When cells entered the stationary phase, it gradually decreased down to $5 \%$. Triple sulfur isotope compositions of intracellular sulfate were aligned well along the ${ }^{33} \mathrm{~S}$ enriched mass-dependent array with the mean deviation from the array being 4\%o (Figure 6B). The $\delta^{34} \mathrm{~S}$ value of APS decreased from $22 \%$ to $-2 \%$ over the course of experiment. The overall pattern of $\delta^{34} \mathrm{~S}_{\mathrm{APS}}$ followed that of intracellular sulfate, but APS was always estimated to be depleted in ${ }^{34} \mathrm{~S}$ relative to co-existing sulfate. Also, the $\delta^{33} \mathrm{~S}$ values of APS deviated from the experimental massdependent array by up to $35 \%$ (Figure 6B). Despite the limited data available, the $\delta^{34} \mathrm{~S}$ values of intracellular sulfate and APS showed an apparent linear relationship. No sulfur isotope measurements could be made on intracellular sulfite and thiosulfate due to its very low cellular abundance.

\section{Discussion}

\subsection{Assessment of concentrations and isotope compositions of intracellular sulfur metabolites}

This is the first experimental measurement of intracellular sulfur metabolite levels and their isotopic compositions, using actively respiring bacterial cells. Such novelty requires us to carefully evaluate the quality and/or limitations of this method with several independent approaches. Procedural and biological reproducibility is examined, and ${ }^{33} \mathrm{~S}$-sulfate is used as an internal control to monitor the incorporation of contaminant external sulfur. Our results are compared with previous experimental and theoretical data.

To assess procedural reproducibility, we split each stationary-phase culture into two separate aliquots and processed them in parallel. Biological reproducibility was also examined by comparing analyses of early stationary phase cells collected from two independent cultures. Duplicate sample processing resulted in up to $15 \%$ variation in intracellular sulfur metabolite content, and similar reproducibility was observed when two independent cultures were compared at early stationary phase (Table 1). Such variability is greater than expected due to analytical errors in ion chromatography $(5 \%)$, but still small relative to the scale of variations throughout the growth cycle. No intracellular sulfate shows a dilution of ${ }^{33} \mathrm{~S}$ spike greater than $4 \%$, and thus, assuming the isotope composition of contaminant sulfur is near $0 \%$, the measured $\delta^{34} \mathrm{~S}$ value of intracellular sulfate would deviate from its original isotopic composition by no more than $2 \%$ (Figure 6). In contrast, sulfur isotope compositions of APS deviate more substantially from the experimental mass-dependent array, indicating the incorporation of external sulfur contamination was as large as $20 \%$. Since reagents and blank samples contain no detectable amount of APS, incorporation of exogenous sulfate after the IC separation step seems more likely. It is noteworthy that intracellular APS contents are about two orders of magnitude lower than those of sulfate, comprising just a few nanomoles of APS per analysis. Consequently, these samples are much more susceptible to contamination.

Little is known about the intracellular concentrations of sulfur metabolites in the actively respiring sulfate-reducing microbes, but the fact that sulfate-reducing bacteria can accumulate sulfate inside the cell has been well known since the work of Furusaka (1961). Cypionka and his colleagues (Cypionka, 1989; Warthmann and Cypionka, 1990; Stahlmann et al., 1991; Krebe and Cypionka 1992) extensively investigated the intracellular accumulation of sulfate by a wide range of sulfate- 
reducing microbes, showing that sulfate concentrations were almost always higher inside the resting cell than outside. The accumulation factor (inside/outside ratio) decreased as the ambient sulfate concentration increased. Here we calculate the concentration of intracellular sulfate using a conventional cellular volume to dry weight ratio of $1.4 \mu \mathrm{L} / \mathrm{mg}$ (Varma et al., 1983), used in the earlier sulfate accumulation studies (Cypionka, 1989; Warthmann and Cypionka, 1990; Stahlmann et al., 1991), and compare intracellular and extracellular concentrations of sulfate (Figure 5). In contrast to previous work, our data show intracellular sulfate concentrations to be much lower than extracellular during exponential growth. Since the accumulation experiments prevented active sulfate reduction via low temperature or presence of $\mathrm{O}_{2}$ (Cypionka, 1989; Warthmann and Cypionka, 1990; Stahlmann et al., 1991), relatively low intracellular sulfate levels during the exponential phase are presumably due to the rapid consumption of sulfate by vigorous sulfate reduction. During the transition to stationary phase, however, intracellular sulfate concentrations exceed the external levels, resulting in accumulation factors similar to those reported by previous experiments. Thus, drastic changes in the intracellular sulfate levels at different growth stages not only confirm the previous findings, but describe the effect of active respiration on the intracellular sulfate accumulation.

Intracellular APS and sulfite concentrations have not been previously measured, but recent modeling work has predicted sub-micromolar levels of APS and millimolar levels of sulfite in the cell (Wing and Halevy, 2014). Such high ratios of sulfite to APS, however, were not observed in this study. Instead, intracellular APS contents were higher than those of sulfite except for late stationary phase cells. Because Wing and Halevy's model assumes a steady state condition, it might be misleading to compare their model prediction directly with our results, where the concentrations of intracellular sulfur metabolites change rapidly, especially during the late exponential growth phase (Figure 5). However, it is also unlikely that a non-steady state process is solely responsible for the several orders of magnitude discrepancy between model and observations persisting from exponential growth to early stationary phases. In Wing and Halevy's model, the reduction of APS and sulfite is assumed to be coupled to oxidation of menaquinone. Since its midpoint potential $\left(E_{0}{ }^{\prime}=-74 \mathrm{mV}\right)$ might allow APS reduction $\left(E_{o}{ }^{\prime}=-60 \mathrm{mV}\right)$ but not sulfite reduction $\left(\mathrm{E}_{\mathrm{o}}{ }^{\prime}=-116 \mathrm{mV}\right)$ at standard state, the ratio of reduced to oxidized menaquinone is assumed to be 100:1, generating a more favorable redox potential $\left(\mathrm{E}^{\prime}=-129 \mathrm{mV}\right)$. Under these conditions, the reduction of APS is still favored relative to sulfite, thereby resulting in a high sulfite/APS ratio of up to 1,000:1. Here we ran the same model, varying redox potentials for the electron carriers coupled to APS and sulfite reduction individually (Figure 7). These results predict that the ratio of sulfite to APS is sensitive to the redox potential of the associated electron carriers. For example, with an electron donor for sulfite reductase having a redox potential of $-200 \mathrm{mV}$, the resulting sulfite/APS ratio could be less than 0.1 . When grown with lactate as an electron donor, incompletely-oxidizing sulfate reducers like $D$. alaskensis first oxidize lactate to pyruvate and then pyruvate to acetyl-CoA. These two redox pairs have $\mathrm{E}_{\mathrm{o}}$ ' values of -190 $\mathrm{mV}$ and $-480 \mathrm{mV}$, respectively, and sulfate-reducing microbes have other electron carriers with midpoint potentials much lower than that of menaquinones, such as $\mathrm{NADH}\left(\mathrm{E}_{\mathrm{o}}{ }^{\prime}=-320 \mathrm{mV}\right)$ or ferredoxin $\left(E_{\mathrm{o}}^{\prime}=-398 \mathrm{mV}\right)$. Thus, an electron donor with a redox potential of $-200 \mathrm{mV}$ or lower is entirely plausible in the presence of a non-limiting supply of lactate (Figure 7). In contrast, the ratio of sulfite to APS increased considerably during late stationary phase, exceeding unity. Such an increase is consistent with model predictions, because lactate depletion should decrease the ratio of reduced to oxidized electron carriers. In summary, a variable intracellular redox level can readily resolve the discrepancy between our measurements and model predictions, as long as the model constraint of a menaquinone electron donor is relaxed.

\subsection{Strong ${ }^{34} \mathrm{~S}$ enrichment of intracellular sulfate}


An incomplete-oxidizing sulfate reducer, D. alaskensis is known to fractionate sulfur isotopes by only a few permil (Leavitt et al., 2014), and the measured sulfur isotope fractionation in our study is also 3.8\%o (Table 2). When sulfate reduction occurs in the presence of a non-limiting supply of lactate, the resulting sulfur isotope fractionation tends to be small, but rarely as low as 4\%o (Detmers et al., 2001; Sim et al., 2011b). Since the dissimilatory sulfate reduction pathway, including sulfate transporters, ATP sulfurylase, APS reductase, and sulfite reductase, is highly conserved (Pereira et al., 2011), D. alaskensis is an ideal model organism for investigating the lower end of the dynamic range of fractionation, in particular, whether or not the sulfur isotope fractionation imposed by intracellular enzymatic reactions diminishes as net fractionation decreases (Figure 1).

Two series of batch culture experiments convincingly demonstrate that sulfate inside the cell is enriched in ${ }^{34} \mathrm{~S}$ relative to that outside of the cell. This pattern is consistent with predictions from models that assume 1) exchange of sulfate across the membrane is limited, and 2) fractionation occurs primarily during intracellular enzymatic reactions (Rees 1973; Brunner and Bernasconi, 2005; Johnston et al., 2007; Bradley et al., 2011; Sim et al., 2011a). In this situation, the preference of sulfate reduction for light isotopes leaves the residual reactant (intracellular sulfate) enriched in ${ }^{34} \mathrm{~S}$. Interestingly, the fractionation between sulfate inside and outside of the cell is up to $49 \%$, demonstrating that the actual fractionation by intracellular enzymes in $D$. alaskensis remains large despite the minimal net fractionation (Figure 6). Note that only two previous pure culture studies have reported net fractionations greater than 50\%o (Sim et al., 2011b; Leavitt et al., 2013). Our results suggest that such large intracellular fractionations may be intrinsic to the dissimilatory sulfate reduction pathway of most organisms, but in many cases that fractionation is not fully expressed due to closed-system behavior.

Considering the cell as a partly closed-system, the magnitude of net ${ }^{34} \mathrm{~S}$ fractionation between sulfate and sulfide $\left({ }^{34} \varepsilon\right)$ is strongly controlled by the extent to which intracellular sulfate becomes ${ }^{34} \mathrm{~S}$ enriched. That enrichment in turn reflects a competition between sulfate exchange across the membrane, which will pull intracellular sulfate $\delta^{4} S$ down towards that of extracellular sulfate, versus enzymatic sulfate reduction, which will push intracellular sulfate $\delta^{4} \mathrm{~S}$ up as a result of normal kinetic isotope effects (Figure 8). Two bounding end-member scenarios can be considered. First, if the rate of sulfate reduction is low relative to that of sulfate exchange across the membrane ('open system', Figure 8A) via the reversible activity of sulfate permeases (Cypionka, 1989), intracellular sulfate will maintain a $\delta^{34} \mathrm{~S}$ value close to that of ambient sulfate, and the produced sulfide will be strongly depleted in ${ }^{34} \mathrm{~S}$ (large ${ }^{34} \varepsilon$ ). Conversely, if sulfate reduction is very rapid relative to exchange across the membrane ('closed system', Figure $8 \mathrm{C}$ ), then intracellular sulfate will be strongly ${ }^{34} \mathrm{~S}$ enriched and produced sulfide will be only slightly depleted $\left(\operatorname{small~}^{34} \mathrm{\varepsilon}\right.$ ). A cell could operate anywhere between these two extremes (Figure 8B), providing a means to explain nearly the entire range of fractionations expressed in nature by sulfate-reducing microbes. The model is very much analogous to those predicting $\mathrm{C}$ isotope fractionation in plant leaves as a function inside/outside $\mathrm{P}_{\mathrm{CO} 2}$ ratios (Farquhar et al., 1989).

Over the course of our batch experiments, sulfate levels are not limiting growth, but the strong enrichment of ${ }^{34} \mathrm{~S}$-sulfate in the exponentially growing cells indicates that most intracellular sulfate is being reduced before it moves back outside the cell. Such distillation of the intracellular sulfate is similar to the mechanism suggested to account for the small sulfur isotope effect during sulfate-limited growth (Habicht et al., 2005). Here we further test this interesting coincidence with a simple model for the reversibility of sulfate transport. Reversibility of a generalized enzymatic reaction is given as

$$
\text { reversibility }(\mathrm{X})=\frac{b}{f}=e^{\Delta G / R T}
$$


where $b$ and $f$ denote backward and forward fluxes, $\mathrm{R}$ the gas constant, $\mathrm{T}$ the temperature, and $\Delta \mathrm{G}$ the free energy change associated with the reaction (Van der Meer et al., 1980; Stoner, 1992; Beard and Qian, 2007). Values of $X$ will vary between zero (unidirectional) and one (fully reversible). The more negative the free energy change is, the less reversible is the reaction. Since sulfate is transported across the membrane simultaneously with protons (or sodium ions), $\Delta \mathrm{G}$ for sulfate uptake is not a simple function of sulfate concentration gradient across the membrane. Rather, it is also related to the transmembrane electrical potential and $\mathrm{pH}$ gradient (Wing and Halevy, 2014).

$$
\Delta \mathrm{G}=n \cdot\left(F \cdot \Delta \Psi+2.3 \mathrm{RT} \cdot \Delta p H_{\text {out-in }}\right)-2 F \cdot \Delta \Psi+2.3 \mathrm{RT} \cdot \log \frac{\left[\mathrm{SO}_{4, \text { in }}\right]}{\left[\mathrm{SO}_{4, \text { out }}\right]}
$$

where $n$ is the number of symported protons, $\Delta \Psi$ is the electrical potential, and $\Delta \mathrm{pH}$ is the $\mathrm{pH}$ gradient across the membrane. Under sulfate replete conditions, the low-accumulating symport with two protons is expressed $(n=2)$, while sulfate limitation increases the stoichiometry up to three protons per sulfate $(\mathrm{n}=3)$ (Krebe and Cypionka, 1992). Since $\Delta \Psi$ and $\Delta \mathrm{pH}$ possess negative values (Cypionka, 1989), an increasing number of symported protons $(n)$ leads to less reversible sulfate uptake, reducing the isotopic fractionation. It is unlikely that $D$. alaskensis cells grown with 10 to $20 \mathrm{mM}$ sulfate transport three protons per sulfate, but the reduced accumulation of sulfate $\left(\left[\mathrm{SO}_{4, \text { in }}\right] /\left[\mathrm{SO}_{4, \text { out }}\right]\right)$ in the exponentially-growing cells could also make sulfate uptake more energetically favored, and thereby less reversible. Assuming typical values of $-150 \mathrm{mV}$ for $\Delta \Psi,-0.5$ for $\Delta \mathrm{pH}$ (Cypionka,1989), and symport with 2 protons, the estimated ratio of intracellular to extracellular sulfate concentrations at the late exponential growth phase $(\sim 0.5$, see the data at $52 \mathrm{hr}$ in Figure 5$)$ would result in a reversibility of $X=0.05$. That is, during exponential growth phase, $\sim 95 \%$ of transported sulfate is reduced to sulfide, rather than leaking back out (Figure 1). Consequently, both sulfate supply and downstream demand have the same effect on the sulfur isotope fractionation by limiting the openness of intracellular sulfate pool, which tracks the reversibility of sulfate uptake (Figure 1). This explains why most batch culture experiments with excess organic substrates have failed to reproduce the large sulfur isotope fractionation recorded in nature.

\subsection{Metabolic response to lactate depletion}

In the modern marine realm, sulfur isotopic offsets between coeval sulfate and sulfide range up to about 70\%o (Sim et al., 2011b). Such large sulfur isotope fractionations by the natural population of sulfate reducing microbes have been related to slow in situ respiration rates resulting from substrate limitation (Leavitt et al., 2013). The expression of sulfur isotope fractionation in a nutrient-replete batch culture may not be the best analogue for those slow-respiring end members, but still, the physiological and sulfur isotopic response of $D$. alaskensis to starvation can provide important clues on the mechanism behind a wide range of fractionation in nature. A few previous studies have investigated the effect of growth stages on isotopic fractionation at a culture scale (Davidson et al., 2009; Matsu'ura et al., 2016), but here we demonstrate how microbial sulfur isotope fractionation changes in response to energy limitation at a sub-cellular scale.

As discussed above, the low concentrations and strong ${ }^{34} \mathrm{~S}$ enrichment of intracellular sulfate demonstrate that sulfate reduction is as fast as sulfate uptake during the exponential growth, but once cells enter stationary phase, the rate of sulfate reduction plummets to below detection limit with decreasing ${ }^{34} \mathrm{~S}$ enrichment of intracellular sulfate. During the early stationary phase, the intracellular quantity of sulfate remained high, making the sulfate transport reversible (Eq. 8). All these results suggest that the rate of sulfate exchange across the membrane substantially exceeds the demand of maintenance respiration. That is, the sulfur isotope fractionation associated with the enzymatic reactions downstream of intracellular sulfate should be fully expressed at the cell level (Figure 8). Note that sulfur isotope fractionation between intracellular sulfate and sulfide was as large as $\sim 50 \%$ o even at the exponential growth phase. Unfortunately, however, since a negligible amount of sulfide 
was produced during the stationary phase compared to the exponential growth phase, it is challenging to show the corresponding increase in sulfur isotope fractionation here. In the first batch experiment, sulfide became isotopically lighter by $0.5 \%$ after the cessation of growth (Table1), which might underpin the increased fractionation by maintenance respiration. It is also worth noting that Matsu'ura et al. (2016) convincingly showed increasing sulfur isotope fractionation upon the cessation of exponential growth using batch cultures of Desulfovibrio desulfuricans. We further consider two different but not mutually exclusive models describing the fractionation of sulfur isotopes in the stationary phase cells. First, according to the Rees model and its later versions (Rees, 1973; Brunner and Bernasconi, 2005; Wing and Halevy, 2014), sulfur isotope fractionation between intracellular sulfate and sulfide would increase up to the equilibrium value (Sim et al., 2011b) with the reversibility reaching near unity at the thermodynamic limit of microbial growth. Alternatively, the important enzymes in dissimilatory sulfate reduction pathway may act as a coherent respiratory complex, including a recently-characterized dissimilatory sulfite reduction system (Santos et al., 2015), where substrates are channeled through the multi-enzyme complex. Compared with reactions involving free intermediates, a substrate-channeled reaction would maintain a relatively constant isotope effect with the reversibility being more tightly controlled. Measuring the isotopic composition of downstream intermediates (e.g. sulfite) may resolve which model is more appropriate, but in either case, slow maintenance respiration must lead to larger sulfur isotope fractionation corresponding to the decrease in ${ }^{34} \mathrm{~S}$ enrichment of intracellular sulfate. Although it deserves further investigation, preferably in continuous culture, this reservoir effect for sulfate - governed by the balance between transmembrane sulfate exchange and enzymatic reduction - is likely responsible for the wellestablished inverse trend between the magnitude of sulfur isotope fractionation and the specific rate of sulfate reduction (Chambers et al., 1975; Sim et al., 2011a; Leavitt et al., 2013; Ono et al., 2014).

Like intracellular sulfate, $\delta^{34} \mathrm{~S}_{\mathrm{APS}}$ decreased as lactate was depleted, but always, APS was depleted in ${ }^{34} \mathrm{~S}$ relative to intracellular sulfate (Figure 6). The sulfur isotope fractionation between APS and intracellular sulfate is unexpected, although it decreases to a few permil as growth ceases.

Given the dilution of ${ }^{33} \mathrm{~S}$-spike in APS, exogenous contamination can account for at most a few permil offset in $\delta^{4} \mathrm{~S}$. APS in the late vegetative phase cells thus appears to be depleted in ${ }^{34} \mathrm{~S}$ by $\sim 20 \%$ o relative to intracellular sulfate (Figure 6). Previously, a negligible equilibrium isotope effect has been presumed between sulfate and APS because of their identical oxidation states (Rees, 1973; Brunner and Bernasconi, 2005). Also, since no sulfur-oxygen bonds are broken during APS formation, a large primary kinetic isotope effect is unlikely (Kohl et al., 2012; Parey et al., 2013). At this point, we cannot specify the mechanism of sulfur isotope fractionation between APS and intracellular sulfate, but possible explanations may include secondary isotope effects due to loosening of the S-O bonds in the transition state, or fractionation associated with the metabolic branch-point between dissimilatory and assimilatory APS reduction. Alternatively, a non-steady state process could potentially account for the observed large isotopic offset at the late exponential growth phase. For example, an increasing backward reaction from sulfite to APS could contribute to the rapidly decreasing trend in $\delta^{34} \mathrm{~S}_{\mathrm{APS}}$ (Figure 1). This explanation is however somewhat difficult to reconcile with the fact that APS was ${ }^{34} \mathrm{~S}$-depleted relative to sulfate at all measured time points.

\section{Conclusions}

We present an optimized analytical approach to measuring concentrations of intracellular sulfur metabolites and their isotopic compositions, providing a direct means of probing the cellular processes that shape sulfur isotope fractionation during dissimilatory sulfate reduction. During batch incubations of D. alaskensis, intracellular sulfate and APS contents gradually increase and peak at the cessation of exponential growth phase. Vigorous sulfate reduction appears to enrich the internal pool 
of sulfate in ${ }^{34} \mathrm{~S}$, but this enrichment diminishes once the cells enter stationary phase. The large ${ }^{34} \mathrm{~S}$ enrichment of intracellular sulfate, up to $49 \%$ relative to extracellular sulfate, is counterbalanced by an apparently large enzymatic fractionation such that the net sulfate/sulfide fractionation is small, only a few permil. We infer that the small net fractionation expressed by this (and probably other) sulfate reducers is a reflection of a strong reservoir effect, rather than reduction of enzymatic isotope effects. As the maintenance respiration abolishes this reservoir effect, the apparent discrepancy between the sulfur isotope fractionation in environmental and laboratory culture studies may reflect the in situ metabolic states of microbes in nature.

Since Thode et al. (1951) first demonstrated the biogenecity of sulfur isotope fractionation between sulfate and sulfide, many studies have linked sulfur isotope fractionation to various environmental factors (Harrison and Thode, 1958; Chambers et al., 1975; Habicht et al., 2005; Canfield et al., 2006; Hoek et al., 2006; Mitchell et al., 2009; Sim et al., 2011a; Sim et al., 2012; Leavitt et al., 2013) and also to specific groups of sulfur metabolizing microbes (Canfield and Thamdrup, 1994; Zerkle et al., 2006), but cellular processes have remained less explored. Here we describe tools to monitor the concentrations and isotopic compositions of intracellular sulfur metabolites. After the pioneering study of dissimilatory sulfite reductase (Leavitt et al., 2015), kinetic isotope effects imparted by other key enzymes are currently also under investigation. Recently, Santos et al. (2015) revealed the role of DsrC, a small subunit of dissimilatory sulfite reductase, and proposed a new biochemical mechanism behind sulfite respiration. All these advances in molecular biology, biochemistry, and isotope biogeochemistry have enabled investigations of microbial sulfur isotope fractionation at a sub-cellular level. In the near future, therefore, we expect to have a firm empirical basis for the quantitative model that links the magnitude of microbial isotope fractionation to their environmental and physiological controls.

\section{Acknowledgements}

This work was supported by an Agouron Geobiology Fellowship to MSS and the Gordon and Betty Moore Foundation Grant GBMF 3306 to VJO and ALS. 


\section{References}

Beard D.A. and Qian H. (2007) Relationship between thermodynamic driving force and one-way fluxes in reversible processes. PLOS ONE 2, e144.

Bevington P.R. and Robinson D.K. (2002) Data reduction and error analysis for the physical sciences. McGraw-Hill, New York.

Bradley A.S., Leavitt W.D., Johnston D.T. (2011) Revisiting the dissimilatory sulfate reduction pathway. Geobiology 9, 446-457.

Bradley A.S., Leavitt W.D., Schmidt M., Knoll A.H., Girguis P.R. and Johnston D.T. (2016) Patterns of sulfur isotope fractionation during microbial sulfate reduction. Geobiology 14, 91-101.

Brunner B. and Bernasconi S.M. (2005) A revised isotope fractionation model for dissimilatory sulfate reduction in sulfate reducing bacteria. Geochim. Cosmochim. Acta 69, 4759-4711.

Canfield D.E., Olesen C.A. and Cox R.P. (2006) Temperature and its control of isotope fractionation by a sulfate-reducing bacterium. Geochim. Cosmochim. Acta 70, 548-561.

Canfield D.E. and Thamdrup B. (1994) The production of 34S-depleted sulfide during bacterial disproportionation of elemental sulfur. Science 266, 1973-1975.

Canfield D.E. and Teske A. (1996) Late Proterozoic rise in atmospheric oxygen concentration inferred from phylogenetic and sulphur-isotope studies. Nature 382, 127-132.

Chambers L.A., Trudinger P.A., Smith J.W. and Burns M.S. (1975) Fractionation of sulfur isotopes by continuous cultures of Desulfovibrio desulfuricans. Can. J. Microbiol. 21, 1602-1607.

Cline J.D. (1969) Spectrophotometric determination of hydrogen sulfide in natural water. Limnol. Oceanogr. 14, 454-458.

Cypionka H. (1989) Characterization of sulfate transport in Desulfovibrio desulfuricans. Arch. Microbiol. 152, 237-243.

Davidson M.M., Bisher M.E., Pratt L.M., Fong J., Southam G., Pfiffner S.M., Reches Z. and Onstott T.C. (2009) Sulfur isotope enrichment during maintenance metabolism in the thermophilic sulfatereducing bacterium Desulfotomaculum putei. Appl. Environ. Microbiol. 75, 5621-5630.

Dawson K.S., Scheller S., Dillon J.G. and OrphanV.J. (2016) Stable isotope phenotyping via cluster analysis of NanoSIMS data as a method for characterizing distinct microbial ecophysiologies and sulfur-cycling in the environment. Front. Microbiol. 7, 774

Detmers J., Brüchert V., Habicht K.S., and Kuever J. (2001) Diversity of sulfur isotope fractionations by sulfate-reducing prokaryotes. Appl. Environ. Microbiol. 67, 888-894

Druhan J.L., Conrad M.E., Williams K.H., N'Guessan L., Long P.E. and Hubbard S.S. (2008) Sulfur isotopes as indicators of amended bacterial sulfate reduction processes influencing field scale uranium bioremediation. Environ. Sci. Technol. 42, 7842-7849.

Farquhar G.D., Ehleringer J.R. and Hubick K.T. (1989) Carbon isotope discrimination and photosynthesis. Annu. Rev. Plant. Biol. 40, 503-537.

Farquhar J., Johnston D.T., Wing B.A., Habicht K.S., Canfield D.E., Airieau S., Thiemens M.H. (2003) Multiple sulphur isotopic interpretations of biosynthetic pathways: implications for biological signatures in the sulphur isotope record. Geobiology 1, 27-36.

Feio, M.J., Zinkevich V., Beech I.B., Llobet-Brossa E., Eaton P., Schmitt J. and Guezennec J. (2004) Desulfovibrio alaskensis sp. nov., a sulphate-reducing bacterium from a soured oil reservoir. Int. J. Syst. Evol. Microbiol. 54, 1747-1752.

Fry B. (1991) Stable isotope diagram of freshwater foodwebs. Ecology 72, 2293-2297.

Furusaka C. (1961) Sulphate transport and metabolism by Desulfovibrio desulphuricans. Nature 192, 427-429.

Habicht K.S., Salling L., Thamdrup B. and Canfield D.E. (2005) Effect of low sulfate concentrations on lactate oxidation and isotope fractionation during sulfate reduction by Archaeoglobus fulgidus strain Z. Appl. Environ. Microbiol. 71, 3770-3777. 
Harrison A.G. and Thode H.G. (1958) Mechanism of the bacterial reduction of sulphate from isotope fractionation studies. Trans. Faraday Soc. 54, 84-92.

Hoek J., Reysenbach A., Habicht K.S. and Canfield D.E.(2006) Effect of hydrogen limitation and temperature on the fractionation of sulfur isotopes by a deep-sea hydrothermal vent sulfatereducing bacterium. Geochim. Cosmochim. Acta 70, 5831-5841.

Johnston D.T., Farquhar J. and Canfield D.E. (2007) Sulfur isotope insights into microbial sulfate reduction: When microbes meet models. Geochim. Cosmochim. Acta 71, 3929-3947.

Jones D.S. and Fike D.A. (2013) Dynamic sulfur and carbon cycling through the end-Ordovician extinction revealed by paired sulfate-pyrite $\delta^{34}$ S. Earth Planet. Sci. Lett. 363, 144-155.

Kandlbinder A., Weiner H. and Kaiser W.M. (2000) Nitrate reductases from leaves of Ricinus (Ricinus communis L.) and spinach (Spinacia oleracea L.) have different regulatory properties. $J$. Exp. Bot. 51, 1099-1105.

Keller-Lehman B., Corrie S.K., Ravn R., Yuan Z. and Keller J. (2006) Preservation and simultaneous analysis of relevant soluble sulfur species in sewage sample. In Proceedings of Second International IWA Conference on Sewer Operation and Maintenance (eds. T. Ertl, A. Pressl, F. Kretschmer and R. Haberl). Sewer Operation and Maintenance SOM 06, Vienna, Austria, pp. 339346.

Kohl I.E., Asatryan R. and Bao H. (2012) No oxygen isotope exchange between water and APSsulfate at surface temperature: Evidence from quantum chemical modeling and triple-oxygen isotope experiments. Geochim. Cosmochim. Acta 95, 106-118.

Krebe B. and Cypionka H. (1992) Protomotive force in freshwater sulfate-reducing bacteria, and its role in sulfate accumulation in Desulfovibrio propionicus. Arch. Microbiol. 158, 183-187.

Leavitt W.D., Bradley A.S., Santos A.A., Pereira I.A.C. and Johnston D.T. (2015) Sulfur isotope effects of dissimilatory sulfite reductase. Front. Microbiol. 6, 1392.

Leavitt W.D., Cummins R., Schmidt M.L., Sim M.S., Ono S., Bradley A.S., Johnston D.T. (2014) Multiple sulfur isotope signatures of sulfite and thiosulfate reduction by the model dissimilatory sulfate-reducer, Desulfovibrio alaskensis str. G20. Front. Microbiol. 5, 591

Leavitt W.D., Halevy I., Bradley A.S. and Johnston D.T. (2013) Influence of sulfate reduction rates on the Phanerozoic sulfur isotope record. Proc. Natl. Acad. Sci. U.S.A. 110, 11244-11249.

Lindgren M. and Cedergren A. (1982) Conditions for sulfite stabilization and determination by ion chromatography. Anal. Chim. Acta 141, 279-286.

Mariotti A., Germon J.C., Hubert P., Kaiser P., Letolle R., Tardieux A. and Tardieux P. (1981) Experimental determination of nitrogen kinetic isotope fractionation: some principles; illustration for the denitrification and nitrification processes. Plant Soil 62, 413-430.

Maharjan R.P. and Ferenci T. (2003) Global metabolite analysis: the influence of extraction methodology on metabolome profiles of Escherichia coli. Anal. Biochem. 313, 145-154.

Matsu'ura F., Sunamura M., Ueno Y. and Urabe T. (2016) Influence of cell's growth phase on the sulfur isotopic fractionation during in vitro microbial sulfate reduction. Chem. Geol. 431, 1-9.

Mitchell K., Heyer A., Canfield D.E., Hoek J. and Habicht K.S. (2009) Temperature effect on the sulfur isotope fractionation during sulfate reduction by two strains of the hyperthermophilic Archaeoglobus fulgidus. Environ. Microbiol. 11, 2998-3006.

Nony P.A., Kennett S.B., Glasgow W.C., Olden K. and Roberts J.D. (2005) 15(s)-Lipoxygenase-2 mediates arachidonic acid-stimulated adhesion of human breast carcinoma cells through the activation of TAK1, MKK6, and p38 MAPK*. J. Biol. Chem. 280, 31413-31419.

Ono S., Sim M.S. and Bosak T. (2014) Predictive isotope model connects microbes in culture and nature. Proc. Natl. Acad. Sci. U.S.A. 111, 18102-18103. 
Parey K., Fritz G., Ermler U. and Kroneck P.M.H. (2013) Conserving energy with sulfate around $100^{\circ} \mathrm{C}$ - structure and mechanism of key metal enzymes in hyperthermophilic Archaeoglobus fulgidus, Metallomics 5, 302.

Paris G., Adkins J.F., Sessions A.L., Webb S.M. and Fischer W.W. (2014) Neoarchean carbonateassociated sulfate records positive $\Delta^{33} \mathrm{~S}$ anomalies, Science $346,739-741$.

Paris G., Sessions A.L., Subhas A.V. and Adkins J.F. (2013) MC-ICP-MS measurement of $\delta^{34}$ S and $\Delta^{33} \mathrm{~S}$ in small amounts o dissolved sulfate. Chem.Geol. 345, 50-61.

Pellerin A., Anerson-Trocmé L., Whyte L.G., Zane G.M., Wall J.D. and Wing B.A. (2015) Sulfur isotope fractionation during the evolutionary adaptation of a sulfate-reducing bacterium. Appl. Environ. Microbiol. 81, 2676-2689.

Pereira I.A.C., Ramos A.R., Grein F., Marques M.C., Da Silva S.M. and Venceslau S.S. (2011) A Comparative Genomic Analysis of Energy Metabolism in Sulfate Reducing Bacteria and Archaea. Front. Microbiol. 2, 69.

Raven M.R., Sessions A.L., Fischer W.W. and Adkins J.F. (2016) Sedimentary pyrite $\delta^{34}$ S differs from porewater sulfide in Santa Barbara Basin: Proposed role of organic sulfur. Geochim. Cosmochim. Acta 186, 120-134.

Rees C. (1973) A steady-state model for sulphur isotope fractionation in bacterial reduction processes. Geochim. Cosmochim. Acta 37, 1141-1162.

Santos A.A., Venceslau S.S., Grein F., Leavitt W.D., Dahl C., Jonston D.T. and Pereira I.A.C (2015) A protein trisulfide couples dissimilatory sulfate reduction to energy conservation. Science 350, 1541-1545.

Sim M.S., Ono S., Donovan K., Templer S.P. and Bosak T. (2011a). Effect of electron donors on the fractionation of sulfur isotopes by a marine Desulfovibrio sp. Geochim. Cosmochim. Acta 75, 4244-4259.

Sim M.S., Bosak T. and Ono S. (2011b) Large sulfur isotope fractionation does not require disproportionation. Science 333, 74-77.

Sim M.S., Ono S. and Bosak T. (2012) Effect of iron and nitrogen limitation on sulfur isotope fractionation during microbial sulfate reduction. Appl. Environ. Microbiol. 78, 8368-8376.

Sim M.S., Ono S. and Hurtegen M.T. (2015) Sulfur isotope evidence for low and fluctuating sulfate levels in the Late Devonian ocean and the potential link with the mass extinction event. Earth Planet. Sci. Lett. 419, 52-62.

Stahlmann J., Warthmann R. and Cypionka H. (1991) $\mathrm{Na}^{+}$-dependent accumulation of sulfate and thiosulfate in marine sulfate-reducing bacteria. Arch. Microbiol. 155, 554-558.

Stoner C.D. (1992) An investigation of the relationships between rate and driving force in simple uncatalysed and enzyme-catalysed reactions with applications of the findings to chemiosmotic reactions. Biochem. J. 283, 541-552.

Thode H.G., Kleerekoper H. and McElcheran D. (1951) Isotope fractionation in the bacterial reduction of sulphate. Research 4, 581-582.

Van der Meer R., Westerhoff H.V. and Van Dam K. (1980) Linear relationship between rate and thermodynamic force in enzyme-catalyzed reactions. Biochim. Biophys. Acta 591, 488-493.

Varma A., Schönheit P. and Thauer K. (1983) Electrogenic sodium ion/proton antiport in Desulfovibrio vulgaris. Arch. Microbiol. 136, 69-73.

Warthmann R. and Cypionka H. (1990) Sulfate transport in Desulfobulbus propionicus and Desulfococcus multivorans. Arch. Microbiol. 154, 144-149.

Widdel F., Kohring G.W. and Mayer F. (1983) Studies on dissimilatory sulfate-reducing bacteria that decomposed fatty acids. III. Characterization of the filamentous gliding Desulfonema limocola gen. nov. sp. nov., and Desulfonema magnum sp. nov. Arch. Microbiol. 134, 286-294. 
Wing B.A. and Halevy I. (2014) Intracellular metabolite levels shape sulfur isotope fractionation during microbial sulfate respiration. Proc. Natl. Acad. Sci. U.S.A. 111, 18116-18125.

Wortmann U.G., Bernasconi S.M. and Böttcher M.E. (2001) Hypersulfidic deep biosphere indicates extreme sulfur isotope fractionation during single-step microbial sulfate reduction. Geology 29 , 647-650.

Wu Y. and Li L. (2013) Development of isotope labeling liquid chromatography-mass spectrometry for metabolic profiling of bacterial cells and its application for bacterial differentiation. Anal. Chem. 85, 5755-5763.

Zerkle A.L., Farquhar J., Johnston D.T., Cox R.P. and Canfield D.E. (2009) Fractionation of multiple sulfur isotopes during phototrophic oxidation of sulfide and elemental sulfur by a green sulfur bacterium. Geochim. Cosmochim. Acta 73, 291-306. 


\section{Figure Captions}

Figure 1. Dissimilatory sulfate reduction pathway and sulfur isotope effects (A) Classical Rees model for the sulfur isotope fractionation during sulfate respiration (Rees, 1973). The reversibility of sulfate uptake $\left(\mathrm{X}_{1}\right)$ and the sulfur isotope fractionation imparted by reductive enzymatic reactions $\left(\varepsilon_{\text {red }}\right)$ primarily determine the overall fractionation $\left(\varepsilon_{\text {net }}\right)$. Note that the sulfur isotope effect assigned to each enzymatic reaction was inferred but not experimentally tested until recently. (B) Sulfur metabolites and enzymes in the dissimilatory sulfate reduction pathway (Wing and Halevy, 2014). This model was used here to quantify the intracellular ratio of sulfite to APS (see Figure 7). SulP is sulfate permease. Atps is ATP sulfurylase. Apr is APS reductase. Dsr is dissimilatory sulfite reductase. $\mathrm{MK}_{\mathrm{red}}$ and $\mathrm{MK}_{\mathrm{ox}}$ stand for the reduced and oxidized forms of menaquinone, respectively. ETC refers to the electron transfer complex. (C) Recent advances in understanding the dissimilatory sulfite reduction and the associated sulfur isotope effect. Santos et al. (2015) revealed the role of DsrC, a small subunit of dissimilatory sulfite reductase, and Leavitt et al. (2015) conducted the first enzyme-specific sulfur isotope experiments, showing that the ${ }^{34} \mathrm{~S} /{ }^{32} \mathrm{~S}$ fractionation during the first step of sulfite reduction was $15 \%$.

Figure 2. Sequential elution of different sulfur compounds using the AS11-HC column with a KOH gradient. This chromatogram was obtained from a mixed standard solution. The separation was monitored by both conductivity (thin black line) and UV absorbance (thick gray line).

Figure 3. Schematic diagrams showing the data screening based on isotope dilution. (A) Due to the ${ }^{33}$ S-sulfate spike, sulfur isotopic compositions of sulfur metabolites evolve along the new massdependent fractionation line, which is parallel to the terrestrial mass-dependent fractionation line $\left(\delta^{33} \mathrm{~S}\right.$ $\approx 0.515 \cdot \delta^{34} \mathrm{~S}$ ) but offset by about $200 \%$ in terms of $\delta^{33} \mathrm{~S}$. (B) A deviation of measured sulfur isotopic ratios from the new mass-dependent fractionation line indicates the degree of contamination, as illustrated by a series of parallel lines, with $0 \%$ meaning that there is not external contamination and $100 \%$ meaning that all measured sulfur is external contamination. In the absence of ${ }^{33} \mathrm{~S}$ tracer, contamination is difficult to detect because $\delta^{34} \mathrm{~S}$ values of most sulfur contaminants fall within the range produced by microbial processes.

Figure 4. Growth of $D$. alaskensis with lactate as a sole electron donor and the resulting sulfur isotope effect. Vertical broken lines indicate the timing of lactate depletion. Blue, green, and red symbols represent experiment series 1, 2, and 3, respectively. (A) Optical density at $660 \mathrm{~nm}$. (B) Lactate consumption and acetate evolution. (C) Sulfate consumption and sulfide evolution (D) Sulfur isotopic composition of sulfate and sulfide, and their weighted average. The uncertainty of optical density $\left(\mathrm{A}_{660}\right)$ is \pm 0.005 , the concentrations determined by chromatography (lactate, acetate, and sulfate) and colorimetry (sulfide) are subject to an error of $\pm 5 \%$, and the analytical error in the isotope analysis is $\pm 0.2 \%$ o for $\delta^{34}$ S. Propagated errors for the weighted average of $\delta^{34} S_{\text {sulfate }}$ and $\delta^{34} S_{\text {sulfide }}$ are smaller than the symbols. (For interpretation of the references to color in this figure legend, the reader is referred to the web version of this article.)

Figure 5. Dynamics of sulfur metabolites in the dissimilatory sulfate reduction pathway. A gray broken line presents the timing of lactate depletion. Both vertical axes are interchangeable for intracellular metabolites, but external sulfate and sulfide concentrations should be read from the right 
vertical axis. Blue, green, and red symbols represent experiment series 1, 2, and 3, respectively. Procedural reproducibility is shown as vertical error bars where available.

Figure 6. Sulfur isotopic compositions of intracellular sulfate and APS. Blue and green symbols represent experiment series 1 and 2, respectively. (A) A strong enrichment of ${ }^{34} \mathrm{~S}$ in both intracellular sulfate and APS is relieved as cells enter the stationary phase. A vertical broken line indicates the timing of lactate depletion. Procedural reproducibility for $\delta^{34} S$ measurement is shown as vertical error bars where available. (B) Triple sulfur isotope ratios of intracellular sulfate and APS. Upper and lower solid lines represent ${ }^{33} \mathrm{~S}$-spiked and terrestrial mass-dependent fractionation lines, respectively. A dotted line exemplifies the mixing trend between the intracellular sulfate and the presumed contaminant with the $\delta^{34} \mathrm{~S}$ value of $0 \%$. Note that sulfur isotopic compositions of intracellular sulfate plot close to the ${ }^{33} \mathrm{~S}$-spiked line, but those of APS deviate from the line by up to $35 \%$. As in panel (A), procedural reproducibility for $\delta^{33} \mathrm{~S}$ measurement is shown as vertical error bars where available.

Figure 7. Influence of the electron donating reactions for APS and sulfite reduction on the relative abundance of APS and sulfite. Contours represent the ratio of sulfite to APS. Intracellular APS and sulfite levels were calculated based on the model proposed by Wing and Halevy (2015), but the reducing potentials of both electron donating reactions were varied from -50 to $-550 \mathrm{mV}$. Note that the original model assumed that the reduction of APS and sulfite is coupled with the oxidation of menaquinone, and the ratio of reduced to oxidized forms is 100 . All calculations were made using a specific sulfate reduction rate of $25 \mathrm{fmol} / \mathrm{cell} /$ day and an ambient sulfide concentration of $1 \mathrm{mM}$. An empty diamond indicates the ratio of sulfite to APS predicted by the original model. In our experiment, the ratio of APS to sulfite increases from less than 0.1 to unity throughout the growth transition from exponential to stationary phases.

Figure 8. A generalized scheme showing how ${ }^{34}$ S-enrichment in intracellular sulfate reflects a competition between sulfate exchange across the membrane and enzymatic reduction. Black arrows indicate $\mathrm{SO}_{4}{ }^{2-}$ uptake and leak, while white ones show the enzymatic reduction and subsequent release of $\mathrm{H}_{2} \mathrm{~S}$ out of the cell. Size of these arrows represents relative rate of sulfur flux, and the vertical position indicates sulfur isotope ratios $\left(\delta^{34} S\right)$. Note that the sulfur isotope mass balance is always maintained at a cellular level, and only reductive reactions are isotope-sensitive; Vertical double head arrows indicate either net fractionation (light grey, $\varepsilon_{\text {net }}$ ), the fractionation between external sulfate and sulfide, or enzymatic fractionation (dark grey, $\varepsilon_{\text {red }}$ ) the fractionation between internal sulfate and sulfide. The rate of sulfate uptake is assumed to be constant, but that of sulfate reduction decreases from left to right. In the "closed system" end-member (A), all sulfate moving into the cell is almost quantitatively reduced to sulfide, resulting in negligible isotope fractionation between external sulfate and sulfide $\left(\varepsilon_{\text {net }}\right)$. Instead, a small pool of residual intracellular sulfate becomes strongly enriched in ${ }^{34} \mathrm{~S}$. In the "open system" end-member $(\mathrm{C})$, since the rate of sulfate exchange across the membrane is much faster than that of reductive reactions, intracellular sulfate maintains a $\delta^{34} \mathrm{~S}$ value close to that of extracellular sulfate. Here, sulfur isotope fractionation between external sulfate and sulfide $\left(\varepsilon_{\text {net }}\right)$ reflects the fractionation imparted by intracellular enzymes $\left(\varepsilon_{\mathrm{red}}\right) .(\mathrm{B})$ is intermediate between these two end-members. 
A

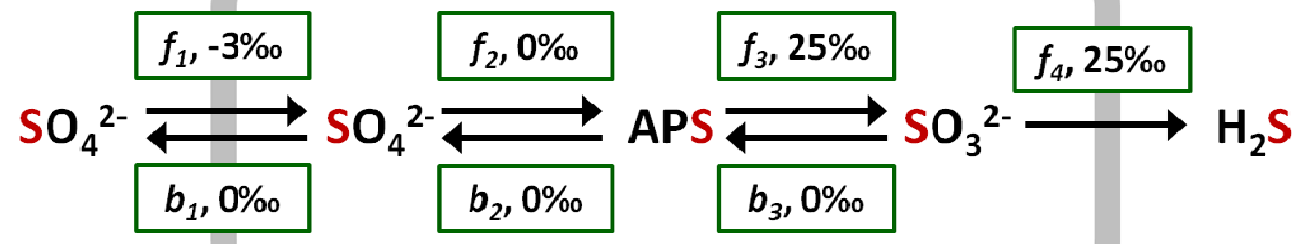

$$
\begin{gathered}
X_{i}=b_{i} / f_{i} \\
{ }^{34} \varepsilon_{\text {net }}=-3+X_{1} \cdot\left(25 \cdot X_{2}+25 \cdot X_{2} \cdot X_{3}\right)=-3+X_{1} \cdot{ }^{34} \varepsilon_{\text {red }}
\end{gathered}
$$

B

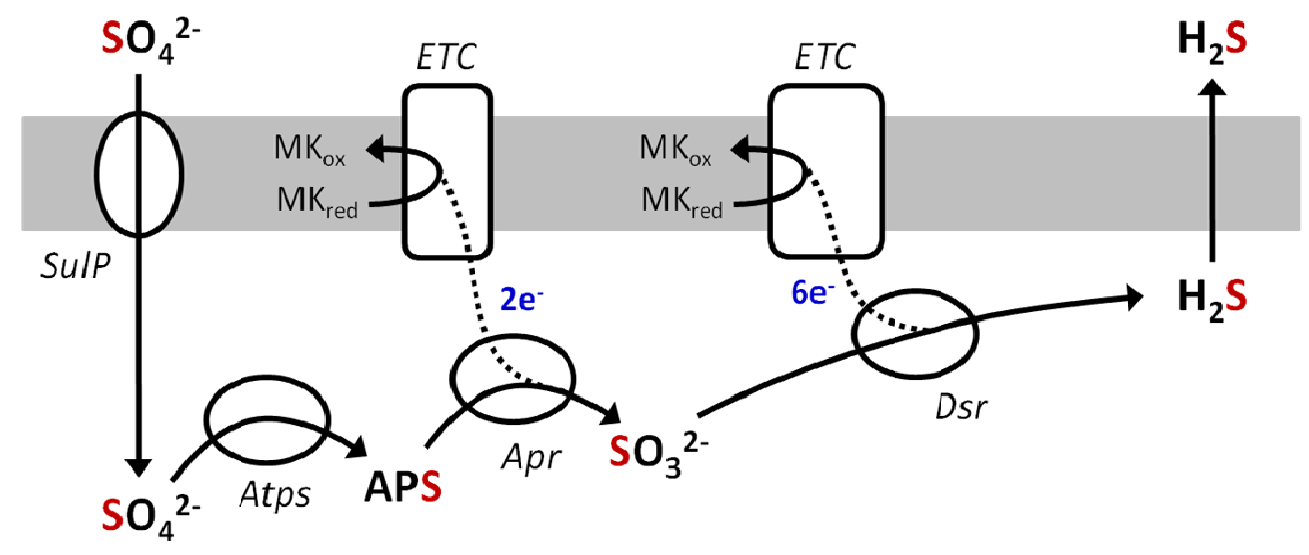

C

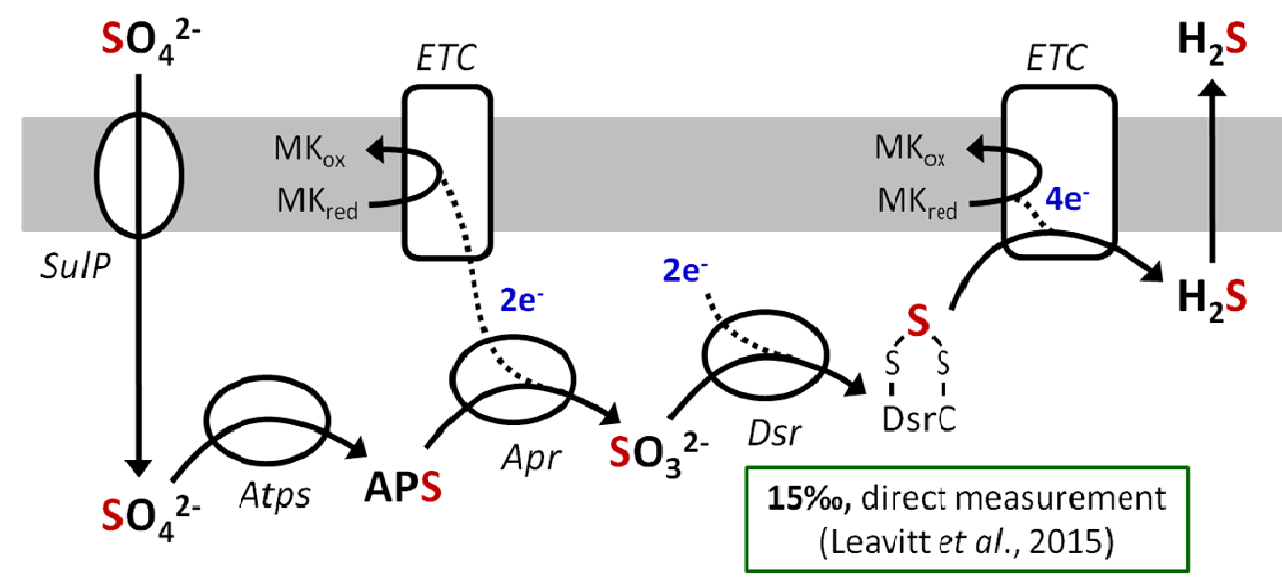




\section{ACCEPTED MANUSCRIPT}

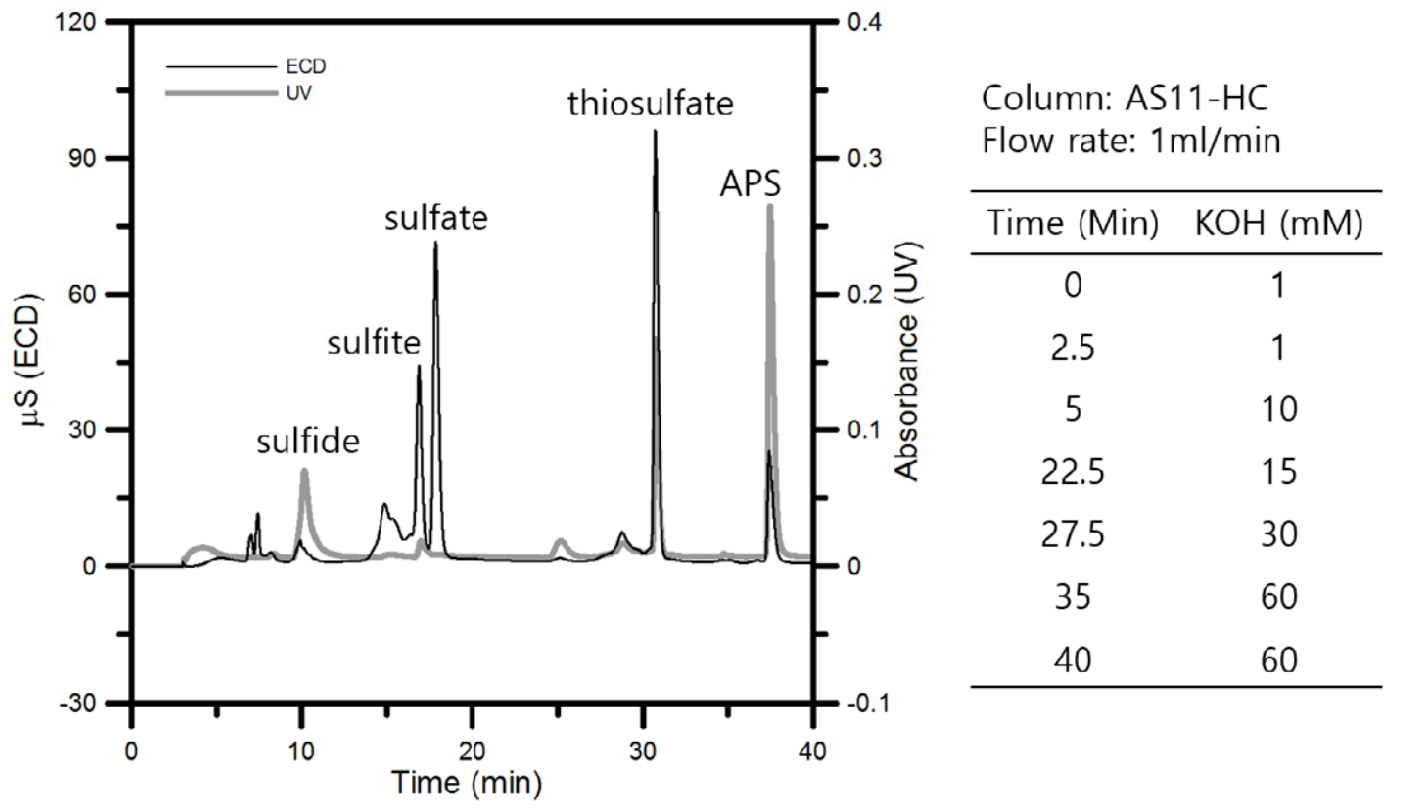



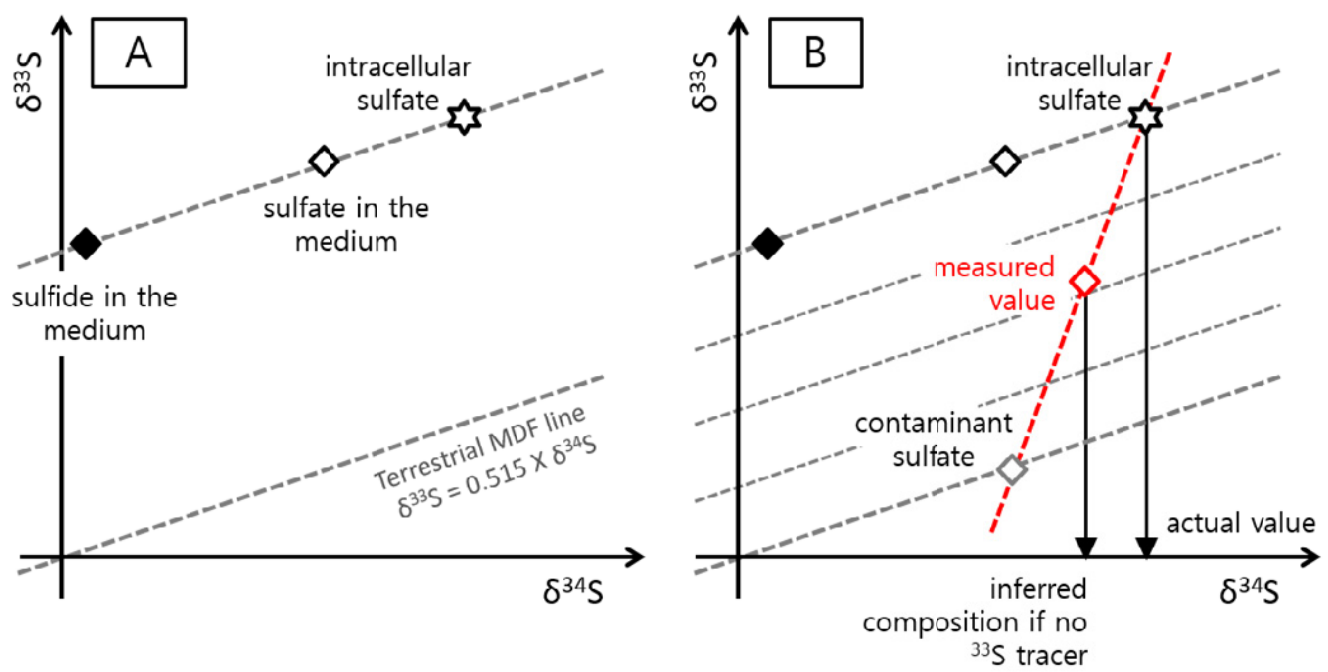

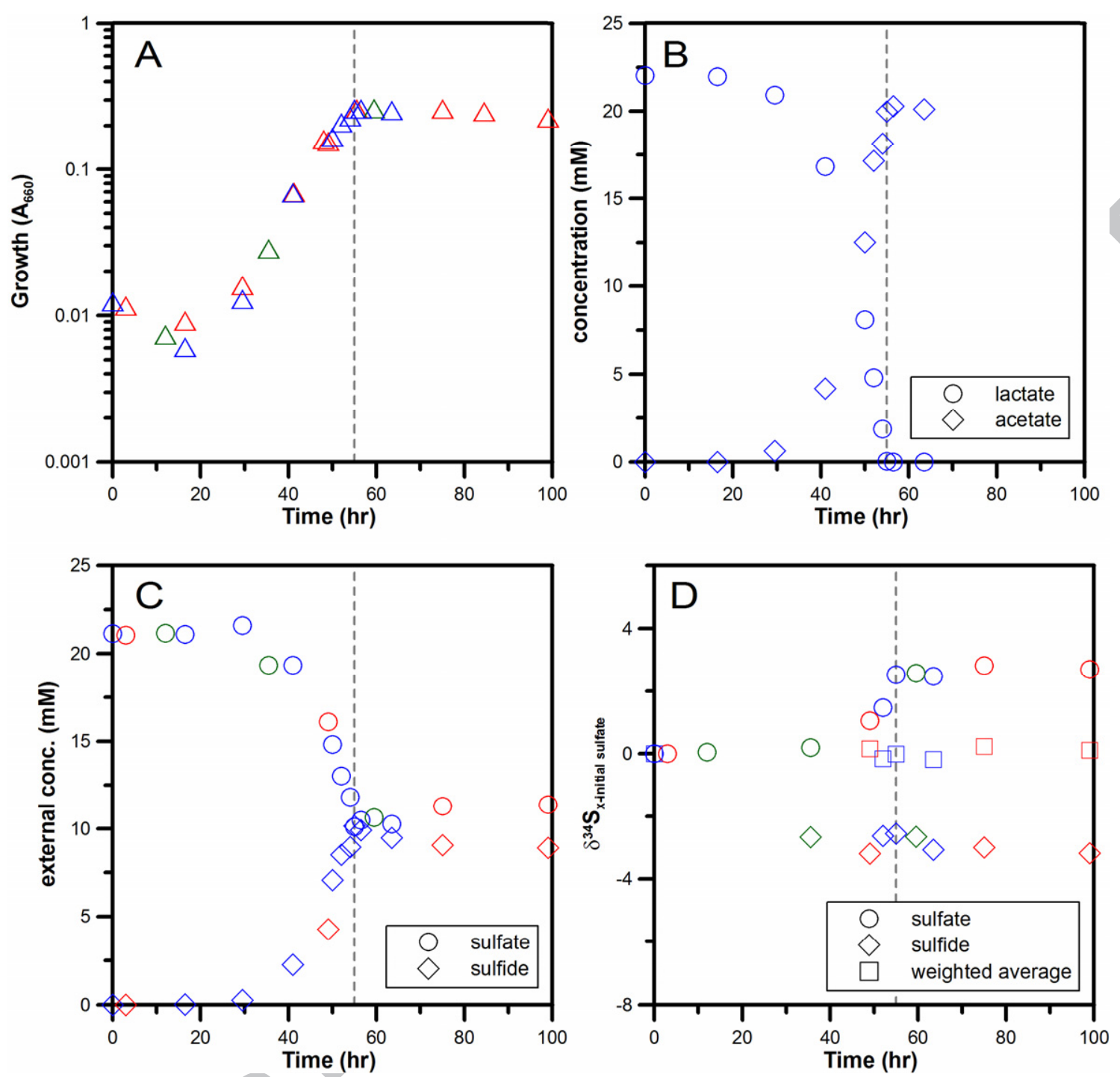


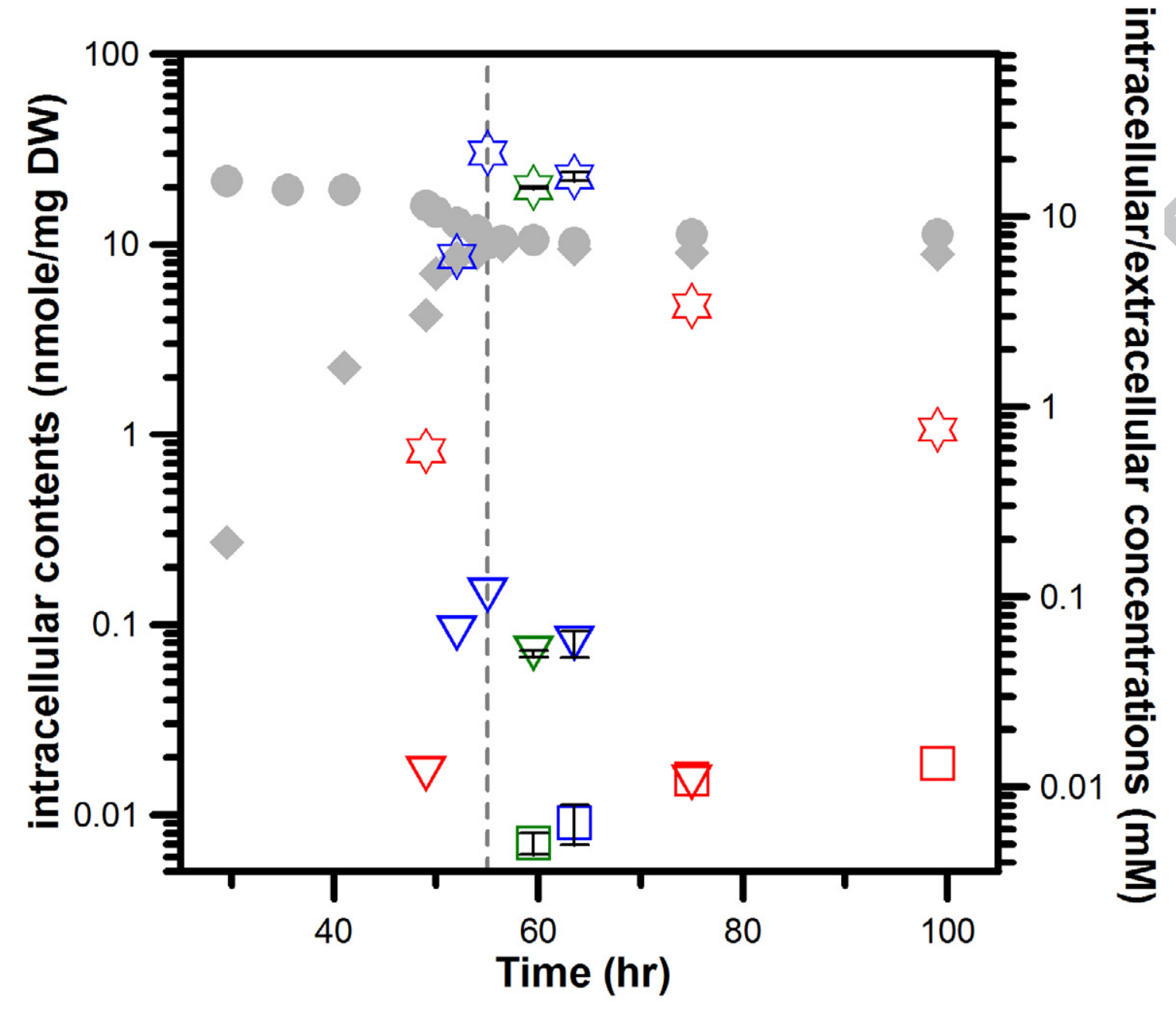

$\sum_{\checkmark}$ intracellular sulfate

$\nabla \quad$ intracellular APS

$\square \quad$ intracellular sulfite extracellular sulfate extracellular sulfide 

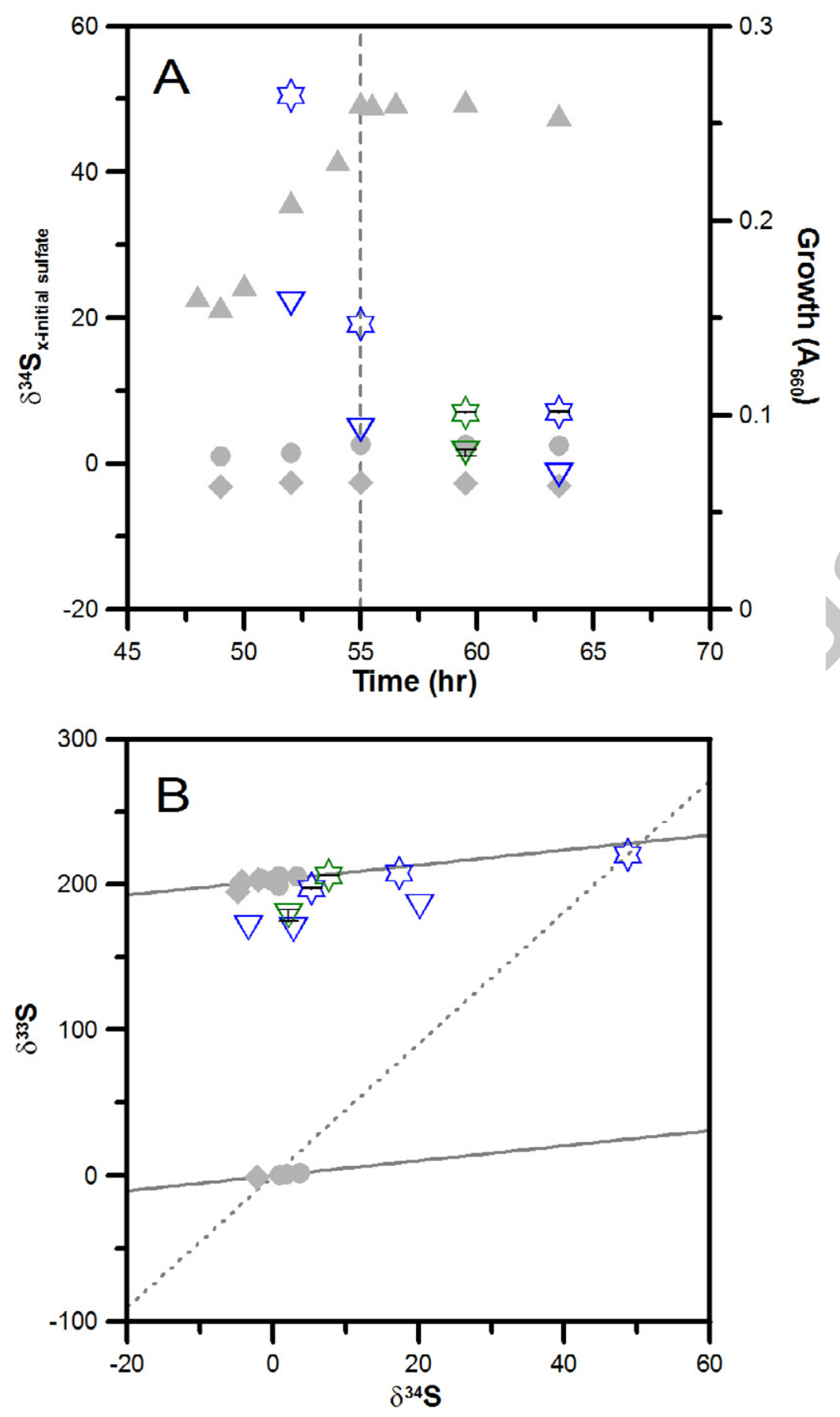

\begin{tabular}{|c|c|}
\hline$\sum$ & intracellular sulfate \\
\hline$\nabla$ & intracellular APS \\
\hline$\Delta$ & Growth $\left(\mathrm{A}_{660}\right)$ \\
\hline - & extracellular sulfate \\
\hline 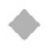 & extracellular sulfide \\
\hline
\end{tabular}




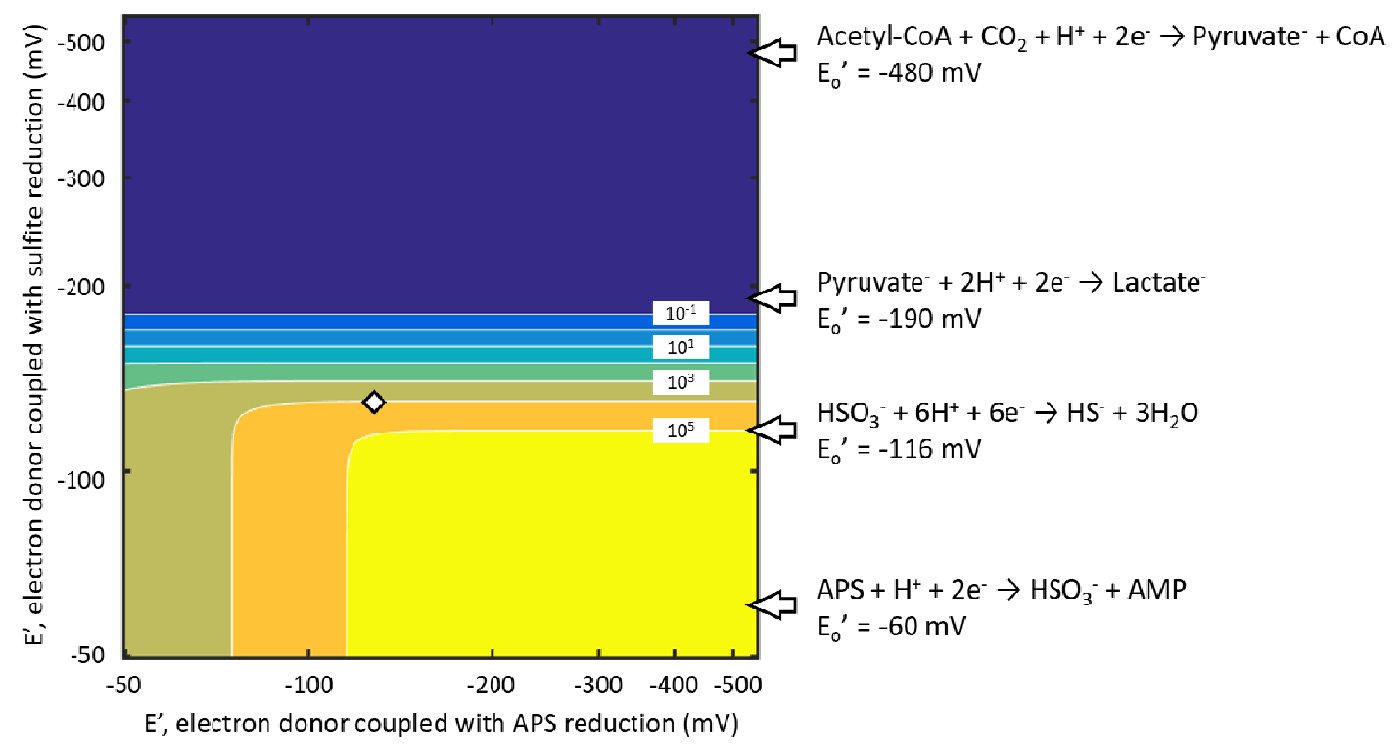




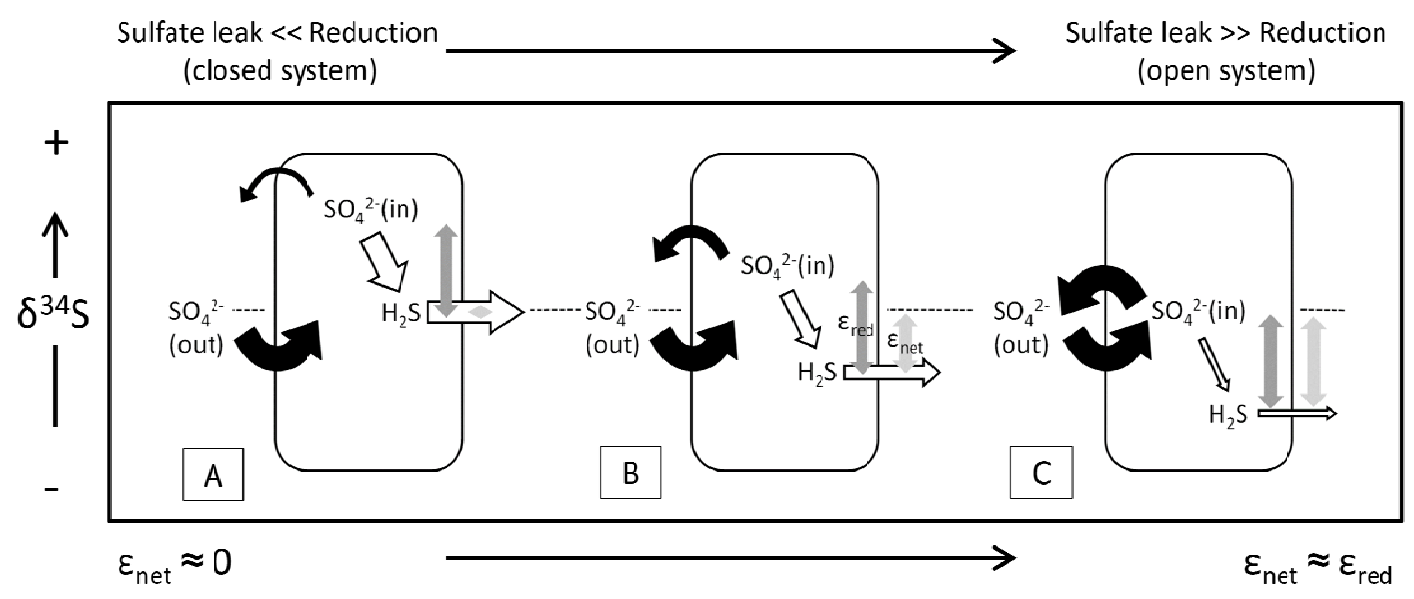


Table 1. Growth, concentration and isotopic data from three batch culture experiments. Measured sulfur isotope compositions are presented as relative ratios to that of VCDT standard $\left(\delta^{34} \mathrm{~S}\right)$ or that of initial sulfate $\left(\delta^{34} \mathrm{~S}_{\mathrm{x}-\mathrm{SO} 40}\right)$. The uncertainty of optical density $\left(\mathrm{A}_{660}\right)$ is \pm 0.005 , the concentrations determined by chromatography and colorimetry are subject to an error of $\pm 5 \%$, and the $2 \sigma$ analytical error in the isotope analysis is $\pm 0.2 \%$ or $\delta^{33} \mathrm{~S}$ and $\delta^{34} \mathrm{~S}$.

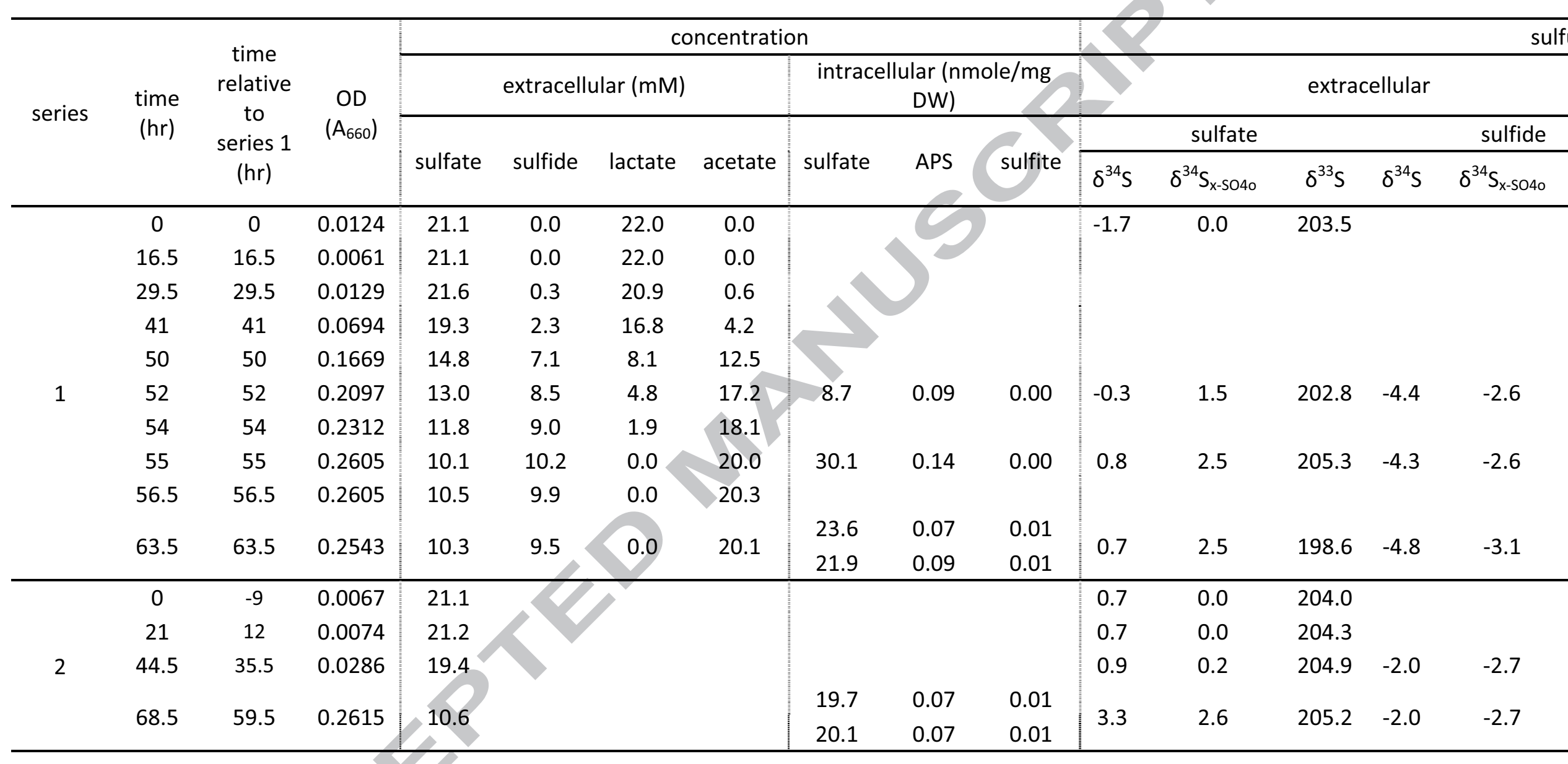




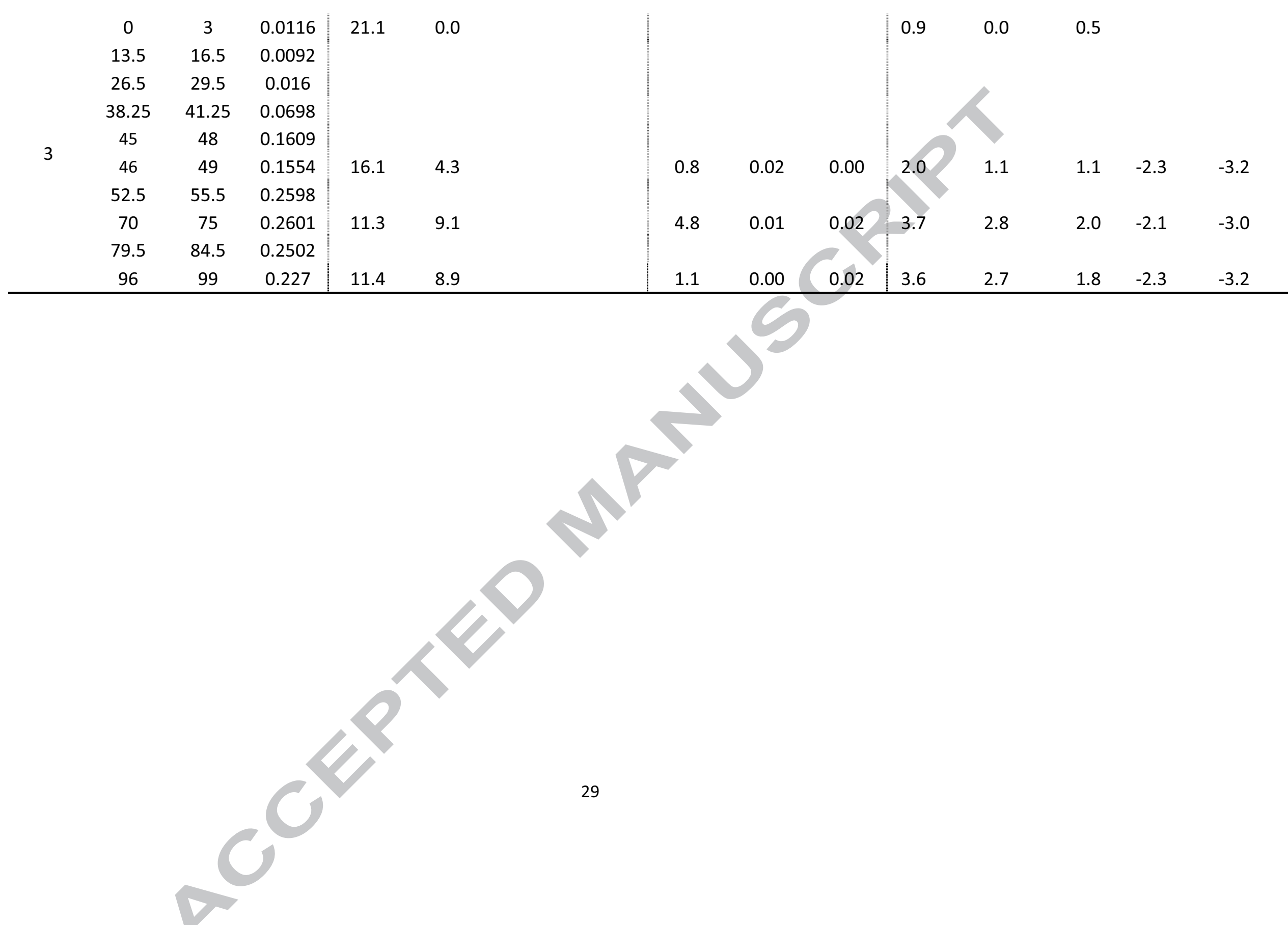


Table 2. Variations in growth kinetics and sulfur isotope fractionation from early to late exponential growth phases. Specific sulfate reduction rate here could be compared with the cell-specific sulfate reduction rate in previous literatures. The size of D. alaskensis was reported to vary from 1 to $5 \mu \mathrm{m}$ in length and 0.5 to $1.2 \mu \mathrm{m}$ in width (Feio et al., 2004), and assuming the average size of 3 by $0.85 \mu \mathrm{m}$ with spheroidal ends, the volume of a single cell was estimated at $1.5 \mu \mathrm{m}^{3}$. Then, the average cell-specific sulfate reduction rate was calculated to be about $290 \mathrm{fmol} / \mathrm{cell} /$ day according to the cellular volume to dry weight ratio of 1.4 $\mu \mathrm{L} / \mathrm{mg}$ (Varma et al., 1983) and the conversion factor for optical density to dry weight (see section 2.1).

\begin{tabular}{cccc}
\hline & $\begin{array}{c}\text { average for the } \\
\text { entire data set }\end{array}$ & $\begin{array}{c}\text { series 1 } \\
\text { (30 to } 52 \mathrm{hr})\end{array}$ & $\begin{array}{c}\text { series 1 } \\
\text { (52 to } 55 \mathrm{hr})\end{array}$ \\
\hline $\begin{array}{c}\text { growth rate } \\
\left(\mathrm{hr}^{-1}\right)\end{array}$ & $0.10 \pm 0.00$ & $0.11 \pm 0.00$ & $0.07 \pm 0.02$ \\
$\begin{array}{c}\text { growth yield } \\
(\text { A660/mM sulfate) }\end{array}$ & $22.6 \pm 1.7$ & $22.9 \pm 2.7$ & $17.3 \pm 9.1$ \\
$\begin{array}{c}\text { specific sulfate reduction rate } \\
\text { (mM sulfate/A660/hr) }\end{array}$ & $4.4 \pm 0.3$ & $4.5 \pm 0.5$ & $4.0 \pm 2.4$ \\
$\begin{array}{c}\text { sulfur isotope fractionation } \\
\text { (\%o) }\end{array}$ & $3.8 \pm 0.4$ & & \\
\hline
\end{tabular}

